\title{
Post COVID-19 complications, adjunct therapy explored, and steroidal after effects
}

\author{
Charu Sonkar, Vaishnavi Hase, Durba Banerjee, Awanish Kumar, Rajesh Kumar, and Hem Chandra Jha
}

\begin{abstract}
For COVID-19 survivors, defeating the virus is just the beginning of a long road to recovery. The inducibility and catastrophic effects of the virus are distributed across multiple organs. The induction of cytokine storms in COVID-19 patients is due to the interaction of the SARS-CoV-2 virus and the host receptor, leading to various immunopathological consequences that may eventually lead to death. So far, COVID-19 has affected tons of people across the world, but there is still no effective treatment. Patients facing complications of COVID-19 after recovery have shown extensive clinical symptoms similar to that of patients recovering from previously circulating coronaviruses. Previous knowledge and literature have opened up ways to treat this disease and manage post-COVID-19 complications, which pose a severe challenge to the health system globally and may exacerbate the fragmentation of diseases. The use of steroids as a treatment has resulted in various health problems and side-effects in COVID-19 patients. This review discusses various post-COVID-19 complications observed and adjunctive therapies used along with common COVID-19 treatment and spotlights their side effects and consequences. This review provides the latest literature on COVID-19, which emphasizes the subsequent complications in various organs, side effects of drugs, and alternative regimens used to treat COVID-19.
\end{abstract}

Key words: COVID-19, cytokine storm, post-COVID-19 complications, corticosteroids, immunotherapy.

Résumé : Pour les survivants de la COVID-19, vaincre le virus n'est que le début d'un long chemin vers la guérison. L'inductibilité virale et les effets catastrophiques qui en découlent sont disséminés dans plusieurs organes. L'induction de tempêtes de cytokines chez les patients atteints de COVID-19 est due à l'interaction entre le virus SRAS-CoV-2 et le récepteur de l'hôte, entraînant diverses conséquences immunopathologiques, susceptibles de mener ultimement à la mort. Jusqu'à présent, le virus a frappé des millions de personnes partout dans le monde, mais il n'existe toujours pas de traitement efficace. Les patients qui présentent des complications de la COVID-19 après leur convalescence ont manifesté de nombreux symptômes cliniques semblables à ceux provoqués par d'autres coronavirus ayant circulé auparavant. Les connaissances antérieures et la littérature ont ouvert une fenêtre sur des moyens de traiter la COVID-19 et de prendre en charge les complications qui surviennent après l'infection, lesquelles posent un grave problème pour le système de santé mondial et ont le potentiel de multiplier les déclinaisons de la maladie. L'utilisation de stéroïdes comme traitement a révélé divers problèmes de santé et effets secondaires chez les patients atteints de la COVID-19. Cette revue de littérature dresse un portrait détaillé des diverses complications post-COVID-19 observées et des traitements adjuvants utilisés en association avec les médicaments couramment employés pour traiter la COVID-19, et met en évidence leurs effets secondaires et leurs conséquences. L'article offre une synthèse de la plus récente littérature sur la COVID-19, qui se concentre sur les complications subséquentes touchant divers organes, les effets secondaires des médicaments et les autres traitements qui ont été utilisés contre cette maladie. [Traduit par la Rédaction]

Mots-clés : COVID-19, tempête de cytokines, complications post-COVID-19, corticostéroïdes, immunothérapie.

\section{Introduction}

The coronavirus disease 2019 (COVID-19) is the cause of the pandemic due to its transmissibility and lethality worldwide. It has drastically impacted the world's healthcare system and economies. ${ }^{1}$ Globally, there have been over 211 million confirmed cases of COVID-19, which includes over 4.4 million deaths as the information received by WHO from national authorities. ${ }^{2}$ Its pathogenesis through viral pneumonia is similar to severe acute respiratory syndrome (SARS-CoV), Middle-eastern respiratory syndrome (MERS-CoV), and influenza. However, COVID-19 patients have reported higher numbers of microthromboses. ${ }^{3}$ These patients have been classified

Received 30 August 2021. Accepted 6 January 2022.

C. Sonkar and H.C. Jha. Department of Biosciences and Biomedical Engineering (BSBE), Indian Institute of Technology Indore, Khandwa Road, Simrol, Indore 453552, India.

V. Hase. School of Biotechnology and Bioinformatics, D.Y. Patil Deemed to be University, Navi Mumbai 400614, India.

D. Banerjee. School of Biotechnology (SOB), Gautam Buddha University (Delhi NCR), Yamuna Expressway, Gautam Buddha Nagar, Greater Noida, Uttar Pradesh 201312, India.

A. Kumar. Department of Biotechnology, National Institute of Technology, Raipur 492010, India.

R. Kumar. Department of Physics, Indian Institute of Technology, Indore 453552, India.

Corresponding authors: Rajesh Kumar (email: rajeshkumar@iiti.ac.in) and Hem Chandra Jha (email: hemcjha@iiti.ac.in).

This paper is part of a special issue dedicated to the careers of Professors Jed Harrison, Charles Lucy, and Richard McCreery of the Department of Chemistry at the University of Alberta.

() 2022 The Author(s). This work is licensed under a Creative Commons Attribution 4.0 International License (CC BY 4.0), which permits unrestricted use, distribution, and reproduction in any medium, provided the original author(s) and source are credited. 
Fig. 1. SARS-CoV-2 spike binds to its receptor human ACE2 through its receptor-binding domain (RBD) and is proteolytically activated by human protease. [Colour online.]

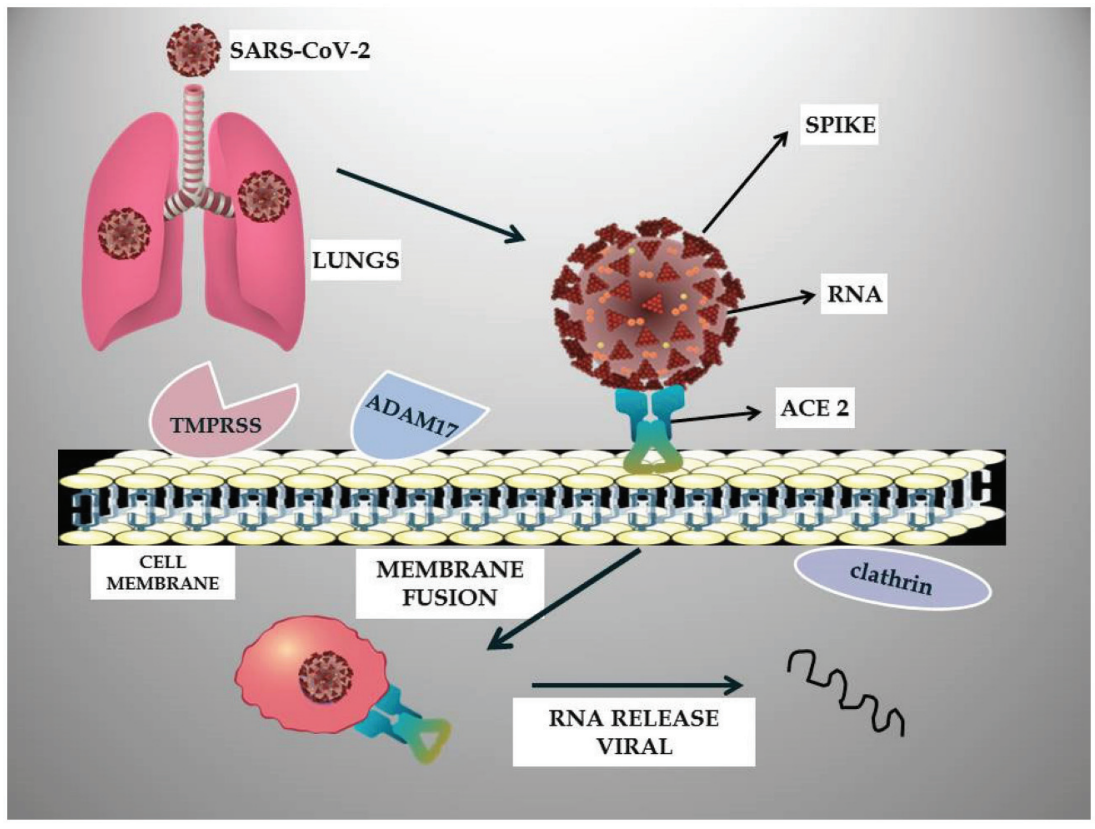

as mild, moderate, or severe based on the intensity of infection. Patients with mild symptoms include shortness of breath or dyspnea, and those with moderate symptoms include lower respiratory disease. Severe and critical symptoms include an oxygen saturation $\left(\mathrm{SpO}_{2}\right)$ of $94 \%$ and respiratory failure, respectively. ${ }^{1}$ Clinical studies and scientific research have suggested the long-term effects of COVID-19, which include multiple organ failure and residual effects, such as fatigue, dyspnea, arthralgia, and cognitive disturbances. Furthermore, these symptoms are the result of COVID-19 induced robust innate responses, leading to inflammatory cytokine production. Survivors of past coronaviruses, such as SARS and MERS, also show similar persistent symptoms. ${ }^{4}$

The United Kingdom's National Institute for Health and Care Excellence (NICE) has divided post COVID-19 symptoms into three categories. The first category is the "post-COVID-19 syndrome", which is considered to be those symptoms that remain for $>12$ weeks, the second category is "long-COVID", which is considered as ongoing symptomatic COVID-19 (symptoms lasting 4-12 weeks), and the third category is the post-COVID-19 syndrome. ${ }^{5}$ Based on some structural and biochemical studies, the receptor-binding domain (RBD) of severe acute respiratory syndrome coronavirus 2 (SARSCoV-2) binds to angiotensin-converting enzyme 2 (ACE2) receptors (Fig. 1), which are present in humans, cats, and ferrets. It is also found in mammalian tissues such as the lungs, kidneys, gastrointestinal tract, liver, blood vessels, and heart. ${ }^{6}$ This review provides up-to-date literature on COVID-19, associated post-COVID-19 complications, affected organs, and side effects of alternative regimens that were acquired for the treatment of COVID-19. Further, this review also presents an comprehensive overview of the promising remedial approaches being used for the management, treatment, and plausible cure of COVID-19. Cytokine storms are considered one of the most catastrophic causes of multiple failures in COVID-19 infection. Excessive infiltrations of the inflammatory cells like monocytes and neutrophils into lung tissue leads to lung injury. ${ }^{7}$ COVID-19 infection is accompanied by an aggressive inflammatory response with the release of a large amount of pro-inflammatory cytokines in an event known as a "cytokine storm". The host immune response to the SARS-CoV-2 virus is hyperactive and results in an excessive inflammatory reaction. Several studies focusing on cytokine profiles from COVID-19 patients have suggested that the cytokine storm correlates directly with lung injury, multi-organ failure, and unfavorable prognosis of severe COVID-19. The "cytokine storm" results from a sudden acute increase in circulating levels of different pro-inflammatory cytokines including IL-6, IL-1, TNF- $\alpha$, and interferon. This increase in cytokines results in the influx of various immune cells such as macrophages, neutrophils, and T cells from the circulation to the site of infection, with destructive effects on human tissue resulting from destabilization of endothelial cell-to-cell interactions, damage of the vascular barrier, capillary damage, diffuse alveolar damage, multi-organ failure, and ultimately death. ${ }^{8}$

\section{Milieu of COVID-19 and post-COVID-19 complications}

Since 1892, there have been global outbreaks of new lower respiratory tract infections, including Russian influenza, ${ }^{9}$ SARS-CoV, and MERS-CoV, which resulted in high mortality rates ${ }^{10}$ and left survivors with fatigue, persistent shortness of breath, reduced quality of life, ${ }^{11}$ and a significant burden of mental health problems, making it difficult for patients to return to productive employment post-discharge. ${ }^{12,13}$ Long-term pulmonary consequences and physical impairment have been described in survivors. ${ }^{14-16} \mathrm{~A}$ few studies report necrosis of the femoral head and pulmonary fibrosis as the most serious side effects of treatment. ${ }^{14}$

Due to late detection and steroidal use, these epidemics have led to secondary infections such as mucormycosis, cytomegalovirus, and aspergillus, ${ }^{17-19}$ and a relatively large number of health workers have been affected. ${ }^{20}$ As a result of post-Coronavirus therapy and rehabilitation programs, improvements have been observed. Past outbreaks and their sequelae would be beneficial for rehabilitation, ${ }^{21,22}$ and related medical planning of services needed by COVID-19 survivors. ${ }^{23}$

\section{Post-COVID-19 complications and organs involved}

COVID-19 manifestations usually resolve within days; however, some survivors develop a spectrum of surprising complications associated with almost every organ system post-infection and require long-term follow-up. ${ }^{23,24}$ Physicians have noted an abundance 
Fig. 2. Development of cytokine storm post entry of COVID-19 resulting in acute respiratory distress syndrome, post COVID-19 complications, organ damage, and death (in some cases). [Colour online.]

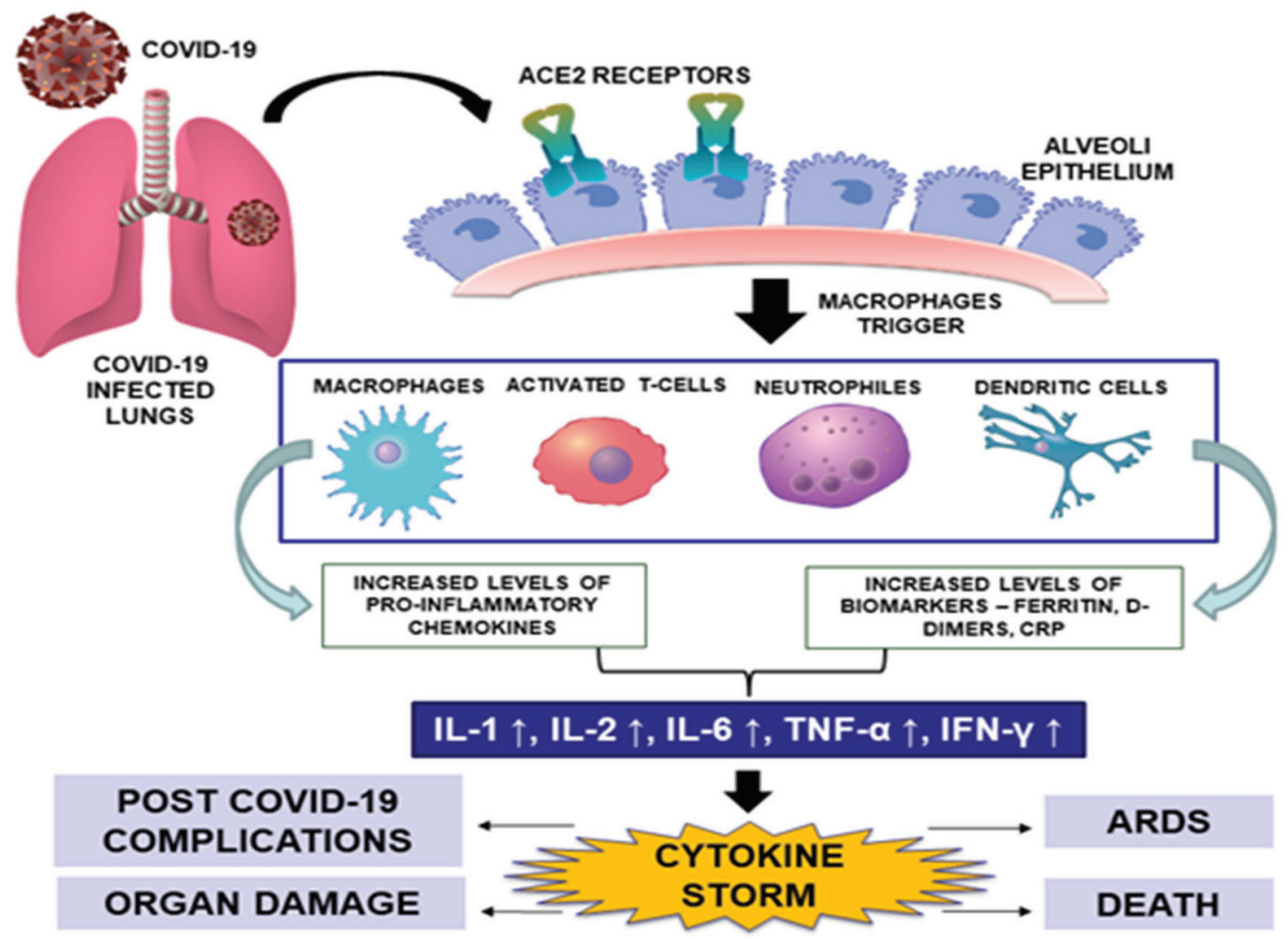

of post-COVID-19 sequelae as the world's fight against COVID-19 continues. ${ }^{25}$ Such complications might be the result of direct viral tissue penetration mediated by the presence of the ACE2 receptor, use of corticosteroids and antibiotics, cytokine storm, vandalized immune system, the hypercoagulable condition reported in conjunction with severe COVID-19, or an combination of all of these ${ }^{11}$ (Fig. 2). A study by the US Centers for Disease Control and Prevention, which interviewed 274 people with proven COVID-19 who had not been admitted to the hospital, found that symptoms can take a long time to resolve, even in young adults. $26 \%$ of interviewees aged 18 to 34 years mentioned that they had not returned to their usual state of health within 14 to 21 days of their test; this number rose to $47 \%$ in those aged 50 years and up. Symptom relief was more likely to be delayed when there were many pre-existing chronic diseases. ${ }^{26}$ Many studies reported the frequent complications persistent in overall body system $\mathrm{s}^{27}$ such as fatigue, cough, headache, chest pain, hair loss, dyspnea, breathlessness, depression, muscle and joint pain, and anosmia/dysgeusia ${ }^{27-33}$ (Table 1). Long COVID-19 was found more frequently in non-hospitalized individuals $(68.3 \%$ vs. $45.3 \%)(P<0.001)$. Hospitalized patients showed greater respiratory symptoms $(95.9 \%$ vs. $85.6 \%)$ during the acute phase, whereas non-hospitalized patients had more neuropsychiatric symptoms (84.4\% vs. $69.5 \% ; P<0.05$ ). The most common reported persistent symptoms in both groups were constitutional and neuropsychiatric problems, although all persistent symptoms were more common in the non-hospitalized group $(P<0.005) .{ }^{74}$ As the virus not only induces acute respiratory distress syndrome (ARDS), but also causes numerous organ damage and its post-viral complications, necessitating critical care should be the aim to drop mortality rates. A detailed review of organizing complications based on the available online literature is provided in Table 1. Statistical data of various countries across the world and in India dealing with these complications are provided in Tables 1 and 2 , respectively.

\subsection{Pulmonary}

The most common long-term consequence of COVID-19 is a serious manifestation of lung disease. The virus destroys the tiny air sacs in the lungs, resulting in reduced diffusion capacity, restricted lung physiological functions, ground-glass opacity, fibrotic changes, breathing difficulties, interstitial thickening, signs of fibrosis, and reduced exercise capacity. ${ }^{42,75}$ Pleural complications may occur due to the pathophysiological changes associated with COVID-19, therapeutic arbitrations, or patient comorbidities (such as pneumothorax, empyema, and pneumomediastinum). ${ }^{76,77}$ A recent study reported ground-glass opacity, parenchymal bands, reticular abnormalities, traction bronchiectasis, and mosaic attenuation as the most common abnormalities observed with a high-resolution computed tomography (HRCT) scan. ${ }^{78}$ Another study including 100 patients showed a diffusing capacity for carbon monoxide (DLCO) $<80 \%$ and a lower serum lactate dehydrogenase (LDH) level postdischarge $^{41}$ (Table 1). Udwadia et al. elucidated interstitial lung disease (PC-ILD) as "the tsunami that will follow the earthquake" due to the continuous spread of virus across the globe. ${ }^{79}$ A follow up study reported that $46 \%$ of patients that recovered from COVID-19 still have a cough and shortness of breath after being cured, and severe cases can have extensive fibrosis of the lungs, resulting in severe dyspnea. ${ }^{80}$ If combined with cardiovascular comorbidities, whether pre-existing or caused by COVID-19, a continuous downturn in lung function will have detrimental cardiopulmonary repercussions. ${ }^{81}$ Although there are no approved therapies or medications for pulmonary complications after COVID-19, research on drug candidates is in progress. ${ }^{78}$ 
Table 1. Representative table for post COVID-19 complications and related studies.

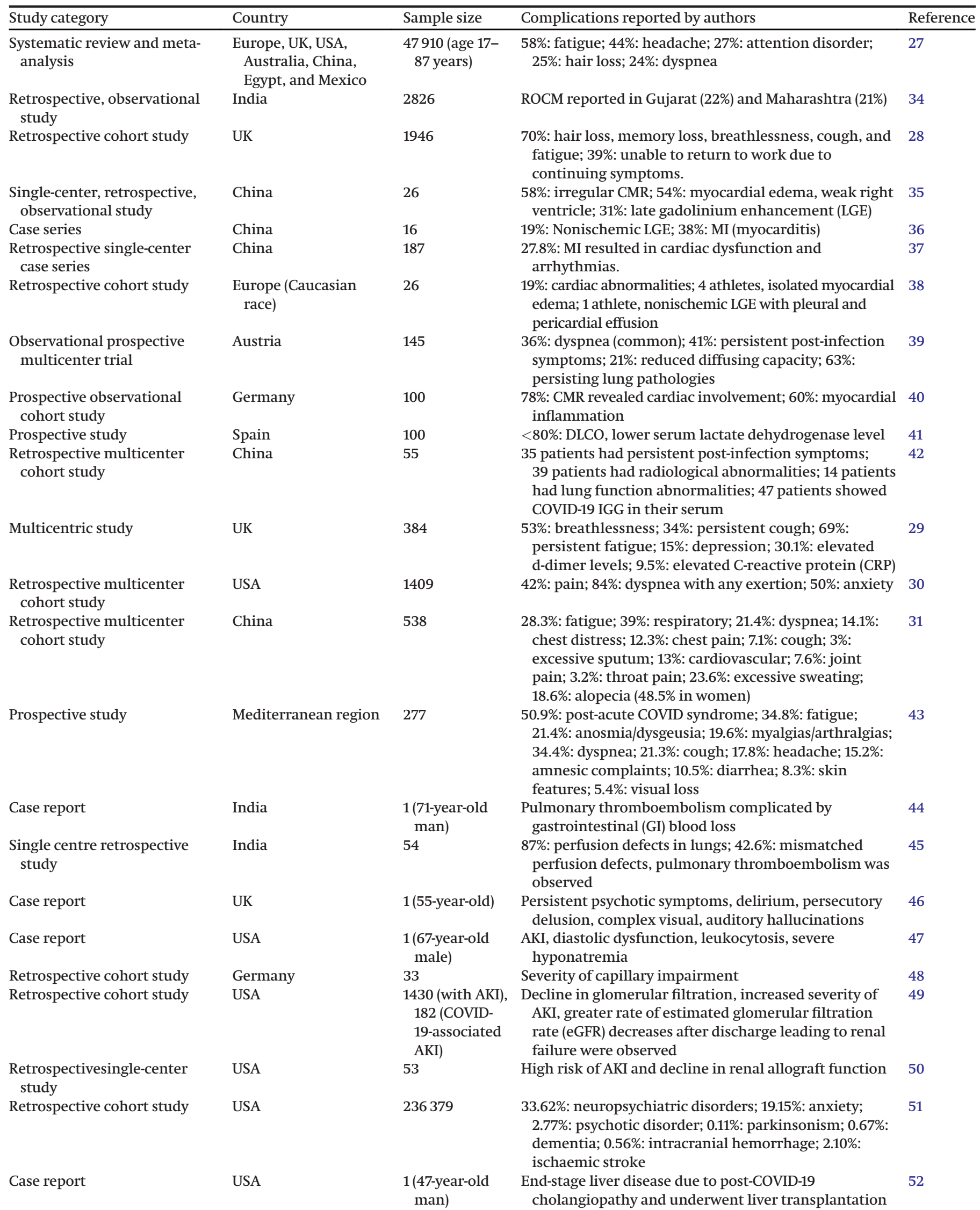


Table 1 (concluded).

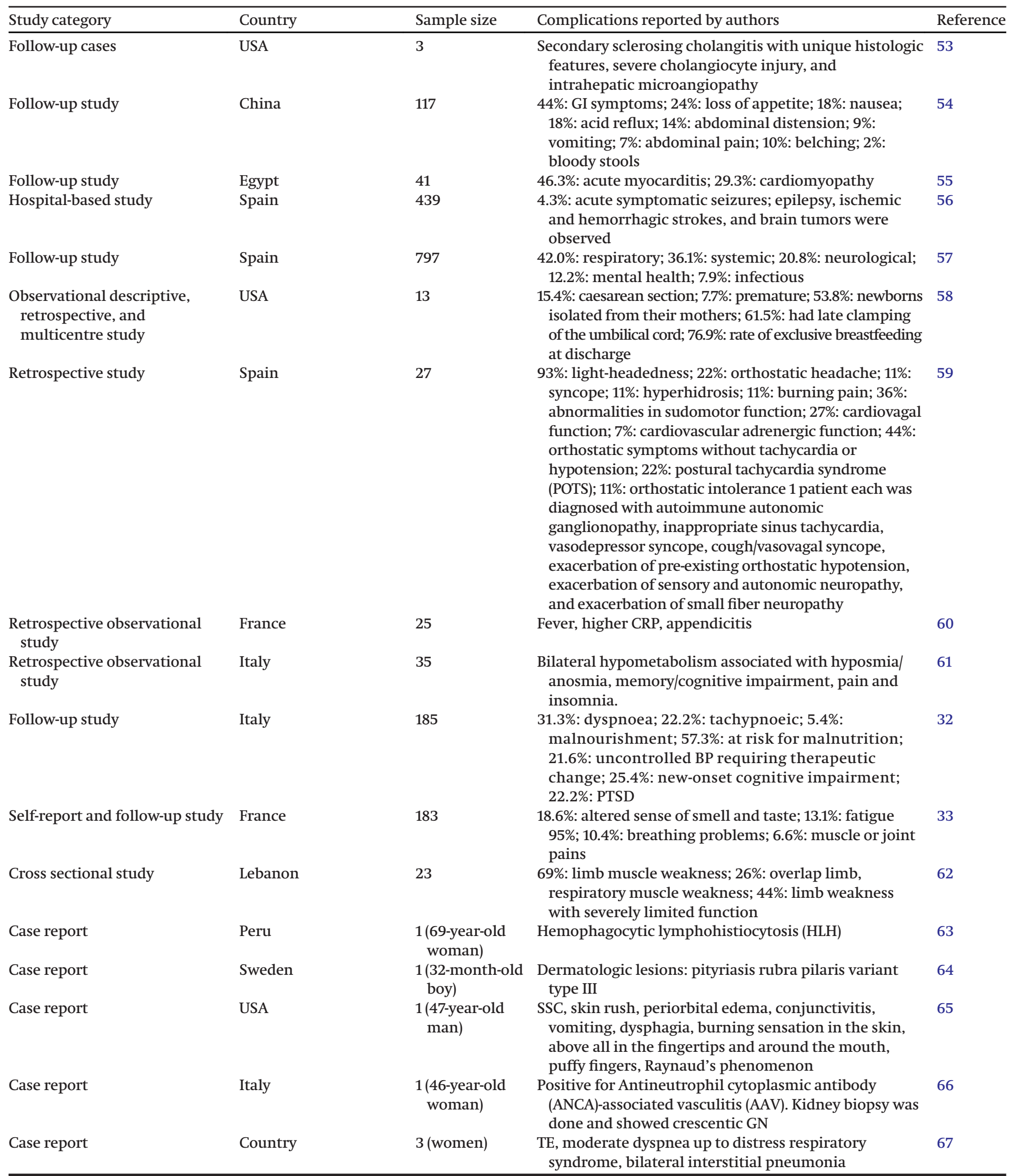


Table 2. Statistical analysis of various reports across India.

\begin{tabular}{lllll}
\hline Serial no. & Post-COVID-19 complications & Incidence (\%) & Sample size & Reference \\
\hline 1 & Cardiovascular & 13.7 & $n=522$ & 68 \\
2 & Pulmonary & 16.4 & $n=522$ & 68 \\
3 & Neurological and heart & 67.2 & $n=1000$ (COVID-19 hospitalized patients) & 69 \\
4 & Hematological & 0 & $n=181$ (children) & 70 \\
5 & Renal & 13 & $n=32$ & 71 \\
6 & Endocrinal & 14 & $n=235$ & 72 \\
7 & Severe psychological & 12.7 & $n=653$ & 73 \\
8 & Musculoskeletal (pain in neck and back region) & 45.81 & $n=537$ & 68 \\
\hline
\end{tabular}

\subsection{Cardiovascular}

Post-COVID-19 complications associated with the cardiopulmonary system are abundant and frequent. ACE2 facilitates entry of the virus into the myocardium, causing myocarditis. Interaction between the virus and ACE2 receptors completely changes the signalling pathways leading to myocardial infarction. ${ }^{11} \mathrm{~A}$ study from Wuhan included 187 COVID-19 patients, of which 77\% survived, including $35.3 \%$ of patients with underlying cardiovascular disease (CVD), including hypertension, coronary heart disease, and cardiomyopathy, and $27.8 \%$ suffered myocardial injury, as indicated by elevated TnT levels (Table 1). ${ }^{35}$ Furthermore, it also reported an increased proliferation of cardiac muscle, leading to the formation of blood clots with necrotic lipid core rupture, causing myocardial infarction related to cardiac insufficiency and arrhythmia (Table 1). ${ }^{37}$ Myocardial fibrosis, tachycardia, ${ }^{11}$ atrial and ventricular arrhythmias, myocarditis, ${ }^{35}$ abnormal cardiovascular magnetic resonance imaging (CMR) findings, ${ }^{35}$ nonischemic late gadolinium enhancement (LGE), ${ }^{36,38}$ acute coronary syndrome (ACS), acute myocardial infarction (MI) or stroke, prolonged hypotension, increased cardiometabolic demand, and sudden cardiac death are some of the common complications observed in survivors (Table 1). ${ }^{24,82,83}$ Acute cardiac injury, which manifests as Takotsubo syndrome (TTS) in female patients, has also been reported. ${ }^{84}$ As with other organ systems, this is especially common in older people with pre-existing comorbidities. Patients with cardiovascular complications or persistent cardiac symptoms during an acute infection can be monitored by continuous clinical, echocardiographic, and electrocardiographic follow-up. ${ }^{4}$

\subsection{Neurologic and head, eye, ear, nose, and throat (HEENT)}

COVID-19 causes direct damage to the nerves by invading multiple nervous cells, including macrophages, microglia, or astrocytes, primarily due to cytokine storms ${ }^{85-87}$ Approximately $35.6 \%$ of COVID-19 cases present with multiple central nervous system (CNS) manifestations (brain fog, headache, fatigue, acute cerebrovascular disease, decreased consciousness, ataxia, and seizures), peripheral nervous system manifestations (sensory diseases and neuralgia), and neuromuscular injury. ${ }^{88-90}$ A study in 2020 showed that 78 of 214 patients (36.4\%) had various neurological manifestations that involved the CNS, PNS, and skeletal muscles. ${ }^{91,92} \mathrm{~A}$ rapidly accumulating set of clinical studies reveals atypical symptoms of COVID-19 that involve neurological signs, including headaches, anosmia, nausea, dysgeusia, damage to respiratory centers, and cerebral infarction. $^{93}$

The involvement of the nervous system could be due to the direct action of viruses on nervous tissue. The first action can be verified during the acute phase of the disease, and the second action can be verified only after days, weeks, or even months following the acute phase. Coronaviruses can take over nervous tissues involving immunefunctioning macrophages, microglia, or astrocytes and cause damage to the nerve through direct infection pathways (circulatory and neuronal), hypoxia, immune injury, ACE2 enzyme attack, and other mechanisms. These observations need to be considered to provide the background and logic for monitoring affected individuals in an attempt to identify those at risk of developing acute, short-, and long-term neurological complications. In one of the first reports of neurological findings during the COVID-19 outbreak in Wuhan, China, neurological manifestations were present in 78 of 214 patients (36.4\%) and fell into three categories: central nervous system (dizziness, headache, impaired consciousness, acute cerebrovascular disease, ataxia, and seizures), peripheral nervous system (taste impairment, smell impairment, vision impairment, and nerve pain), and musculoskeletal. Stroke, ataxia, seizures, and depressed levels of consciousness were the most common in severely affected patients. ${ }^{92}$

A 6-month-long study concluded that neuropsychiatric disorders, psychotic disorders, parkinsonism, dementia, intracranial hemorrhage, and ischemic stroke ${ }^{94}$ were observed in 236379 COVID-19 patients ${ }^{51}$ (Table 1). In addition, a few reports have also reported incidences of memory loss, ${ }^{95,96}$ Guillain-Barre syndrome, ${ }^{97,98}$ demyelinating polyneuropathy, hypoxic encephalopathy, cerebral venous thrombosis, ${ }^{99} \mathrm{CNS}$ vasculitis, ${ }^{100,101}$ paralysis, ${ }^{88}$ acute myelitis, ${ }^{102}$ corneal small nerve fibre loss, brain fog, ${ }^{103}$ increased DCs, ${ }^{104}$ acute necrotizing encephalopathy (ANE), ${ }^{105}$ and acute disseminated encephalomyelitis (ADEM) ${ }^{106,108}$ as complications observed post-discharge. It was found that the virus penetrates the brain tissue through viremia and directly invades the olfactory nerve, causing anosmia and ageusia. ${ }^{109-112}$ Studies related to hearing loss postinfection have also been on the rise. ${ }^{113,114}$ As the conjunctiva in humans is considered a possible location for COVID-19 transmission, ${ }^{115}$ ocular complications such as endogenous endophthalmitis (EE), ${ }^{116}$ conjunctivitis, chemosis, and swelling of the conjunctiva are being studied. ${ }^{117-120}$

\subsection{Psychological}

The mental mechanisms behind COVID-19 include direct effects of viral infection, immune reactions, corticosteroid treatment, intensive care unit (ICU) stay, social isolation, ${ }^{121}$ and stigma. ${ }^{122}$ Individuals recovering from COVID-19 also undergo a psychological toll. Many studies have reported a higher percentage of people suffering from anxiety (Table 1$),{ }^{30,51}$ depression, impaired cognitive abilities, ${ }^{123,124}$ post-intensive treatment syndrome (PICS), and PTSD. ${ }^{125}$ Vlake et al. concluded in a study of 294 of 622 eligible patients that $16 \%$ and $13 \%$ reported probable PTSD, $29 \%$ and $20 \%$ reported probable anxiety, and $32 \%$ and $24 \%$ reported probable depression at 1 and 3 months after hospital discharge, respectively (Table 1). ${ }^{126}$

\subsection{Gastrointestinal and hepatobiliary}

In individuals with COVID-19, gastrointestinal symptoms and liver damage are frequent (Table 1). ${ }^{127}$ The pathophysiological mechanism behind this occurrence is also considered to be related to the affinity of the ACE2 receptor virus for certain enterocytes in the ileum and colon. ${ }^{128-130}$ The long-term impact of COVID-19 on gastrointestinal systems commonly includes nausea, vomiting, abdominal pain, and gastrointestinal tract bleeding (Table 1), ${ }^{54,120}$ and post-infectious bowel syndrome, dyspepsia, acute bowel ischemia, and gangrene. Huang and colleagues reported that approximately $44 \%$ of 117 patients experienced gastrointestinal symptoms 90 days after discharge. Common complications included loss of appetite 
(24\%), nausea (18\%), acid reflux (18\%), diarrhea (15\%), abdominal distension (14\%), belching (10\%), vomiting (9\%), abdominal pain (7\%), and bloody stools (2\%) (Table 1$)^{52}$ The patient's liver abnormality may not only be due to liver cell damage, but also due to bile duct cell dysfunction and other reasons, such as systemic inflammatory response-induced liver damage. ${ }^{131}$ Cholangiopathy after infection is a special entity of liver injury that has been suggested as a variant of secondary sclerosing cholangitis in critically ill patients (SSCCIP). ${ }^{52}$ However, an independent effect of the infection is difficult to differentiate from other therapies such as antibiotics and antivirals. Furthermore, the infections themselves, the sepsis caused, or the competitiveness of hypoxia may be responsible for these anomalies. ${ }^{23}$ COVID-19 may alter the intestinal microbiota, including enrichment and reduction of helpful commensals in opportunistic species. ${ }^{130,132}$

\subsection{Musculoskeletal}

Quarantine and economic downturns caused by COVID-19 have resulted in physical illnesses developing and exacerbating musculoskeletal disorders (MSDs). ${ }^{133}$ In people with post-acute COVID19 who have never experienced musculoskeletal distress, a study including 23 patients showed that $69 \%$ had limb muscle weakness and $26 \%$ had overlap limb and respiratory muscle weakness (Table 1). ${ }^{62,134}$ Inflammatory reactive arthritis involving various joints, avascular necrosis (AVN), ${ }^{135}$ hemophagocytic lymphohistiocytosis (HLH) (Table 1), ${ }^{63}$ primary septic arthritis, glucocorticoidinduced osteonecrosis of the femoral head (GIONFH), ${ }^{136,137}$ and soft tissue abscesses have been reported as post-COVID-19 complications in many studies. The suggested causes of such complications are fat embolism, fat hypertrophy, coagulopathy, vascular endothelial dysfunction, and bone marrow stem cell abnormalities. ${ }^{136,138}$

\subsection{Endocrine and reproductive}

The key amino acids produced by COVID-19 act as molecular mimics of the host adrenocorticotropic hormone (ACTH), leading to antibodies against specific ACTH residues and indicating a lack of cortisol. Also, ACE2 secretion in the pancreas of normal people is higher than in the lungs, suggesting that the virus may combine with ACE2 in the pancreas to induce pancreatic damage. ${ }^{139}$ Endocrine complications include new or worsening diabetes mellitus control, subacute thyroiditis, and bone demineralization. ${ }^{4}$ In a microscope observation of the adrenal glands of patients with COVID-19, 46\% showed alterations in adrenal gland morphology such as ischemia, hemorrhage, degeneration, and local inflammation. $^{140}$ Serum luteinizing hormone (LH) is remarkably increased, and the ratio of testosterone (T) to LH (T:LH) drops sharply in men with severity of infection. ${ }^{141,142}$ Therefore, the interaction of sperm with these receptors affects its fertility and motility ${ }^{143,144}$ and results in orchitis, ${ }^{145}$ scrotal discomfort, ${ }^{146}$ testicular inflammation, ${ }^{147}$ and impairment of sperm quality. ${ }^{148,149}$ An observational study indicated that $39.1 \%$ of male patients with COVID-19 have oligospermia and $60.9 \%$ of them have a high inflammatory state in their semen. ${ }^{150}$ Stress disorder, erectile dysfunction, and decline in sexual function were also seen at higher rates among healthcare professionals due to exposure to trauma. ${ }^{151}$ Relatively increased expression of ACE2 in the uterus was reported in few studies ${ }^{152}$ that suggest the impact on pregnancy and foetus health (Table 1). ${ }^{58}$

\subsection{Vascular}

Retrospective studies reported $<5 \%$ thromboembolic events in post-acute COVID-19 153 and one-third of patients hospitalized develop thromboembolic complications, such as arterial thromboembolism, microvascular thrombi, myocardial injury/infarction, acute limb ischemia/gangrene, mesenteric ischemia, pulmonary embolism, microvascular dysfunction, cerebral venous thrombosis, ${ }^{154}$ intracardiac thrombosis, ${ }^{155}$ stroke, and vascular inflammation, which may also contribute to the hypercoagulable state and endothelial dysfunction in such patients. ${ }^{99,156-159}$ Kumar et al. and
Sajal et al. reported pulmonary thromboembolism, ${ }^{45}$ which was further complicated by gastrointestinal blood loss ${ }^{44}$ (Table 1). These findings indicate that COVID-19 infection promotes endothelial induction in various organs resulting from viral participation and the host's inflammatory response. Additionally, induction of apoptosis and pyrolysis may play a major role in endothelial cell damage in infected patients. ${ }^{160}$

\subsection{Hematological}

COVID-19 is a systemic infection that destroys the hematopoietic system and homeostasis and is usually related to severe blood hypercoagulability. ${ }^{161}$ Immune disorders caused by steroids, antibiotics, and antibacterial agents ${ }^{162}$ have increased secondary fungal co-infections such as rhino-orbital cerebral mucormycosis (ROCM), COVID-19-associated pulmonary aspergillosis (CAPA) (Table 1), ${ }^{163,164}$ and bacteria co-infections due to Gramnegative bacteria and Staphylococcus aureus susceptibility. ${ }^{34,165}$ The shrinkage of lymphoid organs, as well as the spleen, promotes lymphocytopenia and inhibits the lymphocyte turnaround, which may also be accompanied by substantial cytokine activation. ${ }^{166}$ The connection between multisystem inflammatory syndrome in children (MIS-C) to COVID-19 indicates that post-infectious immunological dysregulation is involved in the pathogenesis that includes fever, headaches, rashes on the skin, severe disease, and the participation of two or more organs. ${ }^{167,168}$ MIS-C has the potential to mimic a wide range of infections, cancers, and rheumatic diseases. ${ }^{169} \mathrm{~A}$ 17-month-old developmentally typical girl with parental complaints of irritability, upper extremity weakness, and gait disturbance. She presented to the hospital affordably and irritably with right-sided nasolabial fold flattening, neck stiffness, left upper extremity rigidity, right upper extremity paresis, bilateral lower extremity hyperreflexia, and truncal ataxia post-infection. ${ }^{170}$ Some of the MIS-C characteristics are similar to Kawasaki, toxic shock syndrome (TSS), and secondary activation syndrome or hemophagocytosis). ${ }^{171}$ The possibility of endothelial injury causing serious problems and a possible mimicry of true myocarditis in adults are the underlying pathological features of MIS after COVID-19. ${ }^{172}$

\subsection{Renal}

COVID-19 patients under prolonged intensive care tend to develop hyperreninemia combined with hypernatremia, hyperchloremia, volume overload, ${ }^{173}$ and glomerulonephritis (GN). ${ }^{66} \mathrm{~A}$ possible role for cytokine release syndrome (CRS) in kidney injury similar to sepsis-associated acute kidney injury (SA-AKI) mainly due to acute tubular necrosis, ${ }^{174}$ in which an unregulated systemic inflammatory response causes renal impairment and decline in renal allograft function ${ }^{49,50,175}$ (Table 1). These changes may lead to persistently elevated blood pressure, ${ }^{24}$ elevated protein levels in urine, and abnormal blood tests. Survivors' kidney autopsies also revealed the presence of the virus in tubular epithelial cells causing blood clots that can choke the kidneys' small blood veins, causing damage. ${ }^{176}$ In the case of complications, the use of dialysis could be necessary.

\subsection{Cutaneous}

The effects of post-viral infection on the skin is warranted as, so far, efforts to determine its characteristics are mainly focused on other body apparatuses. ${ }^{177}$ Several case reports on cutaneous problems post COVID-19 patients have been published. ${ }^{23}$ In certain studies, up to $20 \%$ of COVID-19 patients have skin abnormalities like hemorrhagic bullae with intra-bullae blood clots and dissecting hematomas, liver reticularis, isolated herpetiform lesions, urticarial lesions, vesicular lesions, purpuric lesions, papulosquamous lesions, and petechial rash. ${ }^{23}$ COVID-19 related vasculopathy also causes purpuric eruptions, livedo reticularis, or retiform purpura. ${ }^{178,179}$ Presently, hair loss or alopecia is observed as the most common complication in men. ${ }^{27}$ Telogen effluvium (TE), a common hair loss pattern in women triggered by tension, drugs, pre-existing 
Table 3. Complications with different co-morbidities in COVID-19.

\begin{tabular}{ll}
\hline Disease & Extent of Complication \\
\hline Diabetes and obesity & $\begin{array}{c}\text { Type } 1 \text { or type } 2 \text { diabetes can increase risk of significant COVID-19 symptoms. Having a higher } \\
\text { body mass index that is considered overweight, obese or severely obese also increases the risk. } \\
\text { Chronic kidney or liver disease } \\
\text { Chronic kidney or liver disease can weaken the immune system increasing risk of being seriously } \\
\text { ill with COVID-19. Serious COVID-19 symptoms and taking medications to treat the disease may } \\
\text { have negative effects on the liver. } \\
\text { The prognosis for people with hypertension is strikingly worse when COVID-19 infection is } \\
\text { complicated by myocardial injury and in the presence of cardiovascular disease. Poor blood } \\
\text { pressure control and cardiovascular disease can describe the observed associations between age, } \\
\text { hypertension, and severity of COVID-19 infection. } \\
\text { Neurological disorders, susceptibility was associated with pre-existing dementia; both severity } \\
\text { and mortality were associated with subsequent delirium and altered mental status; besides, } \\
\text { mortality was associated with pre-existing and subsequent dementia and multiple specific } \\
\text { neurological diseases. Heterogeneities were substantial across studies in most analysis. }\end{array}$ \\
\hline
\end{tabular}

diseases, and nutritional insufficiency, was reported (Table 1$).{ }^{67}$ Systemic sclerosis $(\mathrm{SSc})^{65}$ and pityriasis rubra pylori ${ }^{64}$ have recently been reported as skin complications (Table 1). Furthermore, the extent of complications was tabulated among patients with different comorbidities (Table 3).

\section{Repurposing of drugs for preventive measures of COVID-19}

The outbreak of COVID-19 has been considered a public health emergency of great importance. Precautions are necessary to prevent its potential spread, and the lack of drugs during the pandemic makes it important for the patient's diagnosis to maximize each individual's potential treatment for COVID-19. Antiviral therapeutic drugs affect the initial phase of the infection, and the virus is contained primarily within the lower respiratory tract. Thus, the drugs work by interacting with various components of the pathogenic life cycle of SARS-CoV-2, which includes certain stages of adhesion, entry, endocytosis, protein cleavage, and replication. Given the potential for long-term issues and the possibility of re-infection after COVID-19, it is critical to adhere to periodic health examinations and educate individuals about precautionary and preventive measures (Fig. 3). Here, we list the drugs are marketed for COVID-19 treatment. Extensive efforts have been made to fight the virus, including pharmacological and nonpharmacological interventions.

\subsection{Chloroquine and hydroxychloroquine}

Chloroquine (CQ) and hydroxychloroquine (HCQ), both 4aminoquinolines, have antiviral effects and play a major role in the treatment of diseases such as malaria and chronic inflammatory diseases such as rheumatoid arthritis (RA) and systemic lupus erythematosus (SLE). They have proven to be effective drugs by considering many of the early surveys and were found to be effective in targeting specific structures in the virus and more likely to succeed than older drugs that may initially work in the laboratory but lack data supporting clinical use, which suggests finding an immediate medication option to resist SARS$\mathrm{CoV}-2$ infection in patients. CQ and HCQ appear to block viral entry into cells by inhibiting glycosylation of ACE2 host receptors and spike proteins, ultimately inhibiting the entry and post-entry steps. Both of the drugs have been shown to have immunomodulatory effects. A potential mechanism of action for CQ and HCQ was discovered by Fantini et al.; for replication of SARS-CoV-2, those states attach to the spike (S) viral protein of respiratory cells. The $S$ protein utilizes sialic acids and ACE2 receptors connected to the host cell surface gangliosides for entry. The study showed that CQ and HQ had an enhanced affinity for binding to gangliosides and sialic acids. A recent study showed that HQ or CQ alone or in combination with azithromycin (AZT) is helpful in managing the emerging coronavirus. Although both drugs are generally well tolerated, high doses can lead to severe side effects such as myopathy, neuropathy, and cardiomyopathy. ${ }^{183,184}$

\subsection{Umifenovir}

Arbidol (ARB), also known as umifenovir, is a Russian-made broad-spectrum oral antiviral drug that has been issued for the treatment and prophylaxis of influenza. It is a repurposed drug against COVID-19; several in vitro studies performed suggest umifenovir to be a potential inhibitor of SARS-CoV-2 infection and this gained a lot of attention and research focus around the world. It interferes with the interaction between the spike protein of the virus and its associated ACE2 receptors on the host cell. ARB can thus prevent contact and entry of the virus into host cells, avoiding the fusion of the virus lipid shell to the cell membrane and inhibiting COVID-19 infection by interfering with the release of SARS-CoV-2 from intracellular vesicles. However, it is important to evaluate the efficacy and safety of umifenovir in COVID-19. ${ }^{185,186}$

\subsection{Ivermectin}

Ivermectin is a well-known medicine and a broad-spectrum antiparasitic agent used to cure parasitic infestations and is currently approved for controlling and treating filariasis, onchocerciasis, and strongyloidiasis. Since the beginning of the SARS-CoV-2 pandemic, both observational and randomized studies have evaluated ivermectin as an efficient treatment against COVID-19 and prophylaxis infection. Other conjectured mechanisms include inhibition of SARS-CoV-2 3CLPro activity (a protease essential for viral replication), a variety of anti-inflammatory effects, and competitive binding of ivermectin with the viral S protein. Ivermectin attains these antiviral properties mostly by destabilizing importin- $\alpha / \beta$ by binding to it, as it is used by SARS-CoV-2 proteins to translocate into the host cell nucleus, thus exhibiting better binding efficacy rates. $^{187,188}$

\subsection{Nitazoxanide}

Nitazoxanide has been used as the first orally active nitrothiazolesalicylamide broad-spectrum antiparasitic and antiviral prodrug. Previously, nitazoxanide yielded successful results in vitro against COVID-19. Nitazoxanide boosts the host innate immune response, thereby tackling the life-threatening cytokine storm. It functions via various mechanisms, including inhibition of $\mathrm{N}$ protein expression in the virus, suppression of proinflammatory cytokines and interleukin (IL-6) production, and blocking of viral replication. However, further clinical evidence is needed to confirm the actual efficacy of the drug in patients. ${ }^{189,190}$ A list of repurposed drugs has been put forward to fight the disastrous pandemic (Table 4). 
Fig. 3. A holistic strategy to tackle complications during the post COVID-19 care period. [Colour online.]

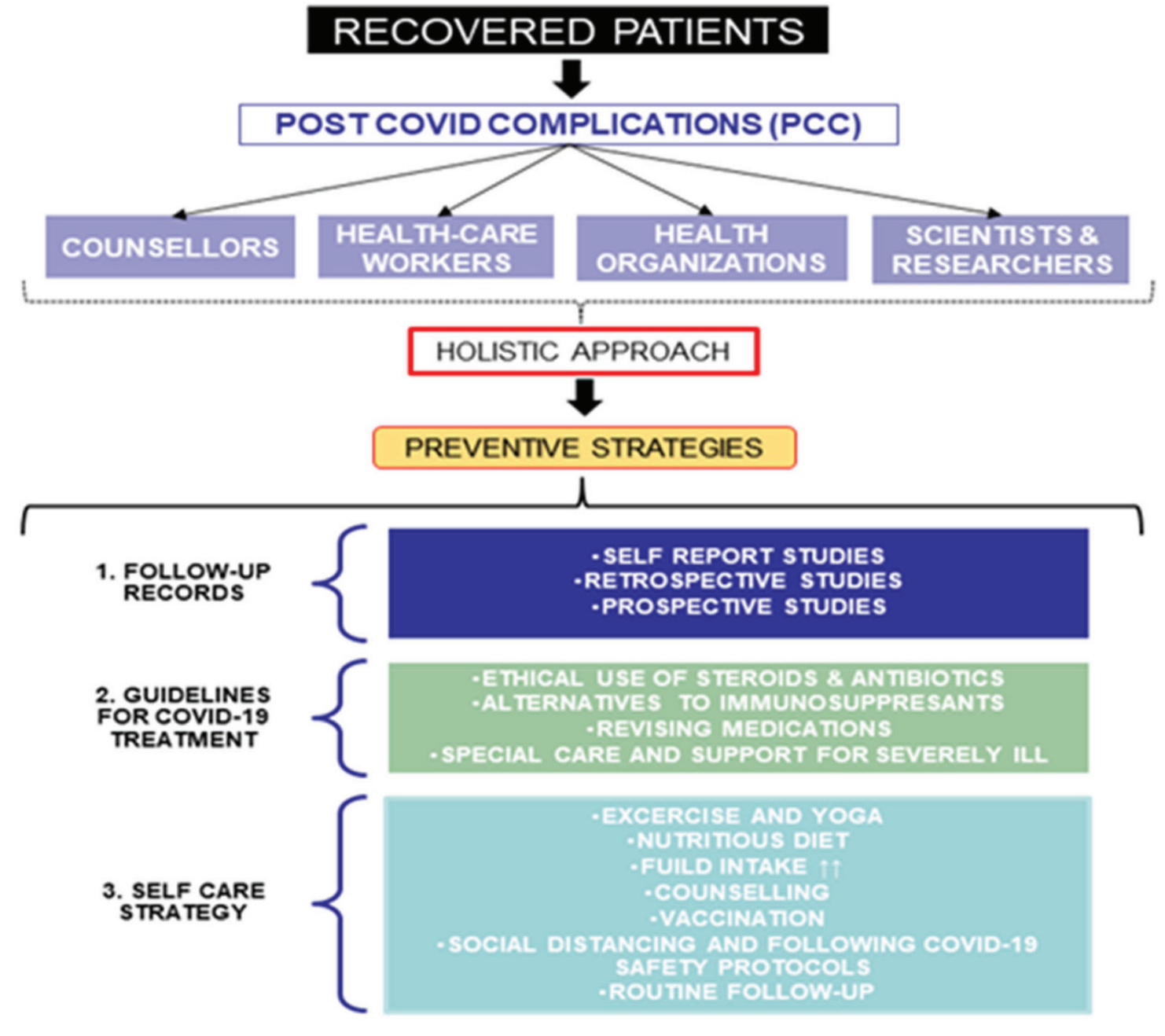

\section{Adjunctive therapeutics for COVID-19 management}

The global impact of the outbreak has led to competition for the discovery of effective therapy and medication, and with no precise therapeutic procedure in vision, it is of extreme importance for healthcare professionals to supervise the clinical manifestations of COVID-19. There are multi-pronged strategies directed towards viral inhibition and modulation of the immune system to ascend its defense. Meanwhile, investigational therapies are being investigated regularly as potential adjuncts to curb the spread and standardize supportive care. ${ }^{194,195}$

\subsection{Heparin}

It functions as an anticoagulant and has tremendous therapeutic functions that are relevant for the treatment of COVID-19-associated clinical manifestations, i.e., neutralisation of inflammatory chemokines and cytokines such as CXCL-1, IL-6, and IL-8. The hyper-inflammatory state produced in turn because of the cytokine storm induces a coagulopathy cascade in patients, leading to ischemia in the hands of the lower limbs and bilateral cerebral infarctions in different vascular territories. The mechanisms by which low-molecularweight heparin (LMWH) could be efficient for COVID-19 patients is argued. Heparin or LMWH has been found to help relieve severe complications and is used in prophylaxis, which was found especially effective in patients who meet the criteria for sepsisinduced coagulopathy (SIC). There is one more characteristic of
heparin/LMWH in the pathogenesis of COVID-19, namely the inhibitory effect on heparanase (HPSE). Increased plasma HPSE activity in COVID-19 patients has been detected. HPSE shed heparan sulphate (HS) fragments, which contribute to the inflammatory extracellular milieu, by the release of sequestered chemokines and (or) the binding of HS fragments to toll-like receptors. ${ }^{196-198}$

\subsection{Corticosteroids}

The cytokine storm is a phenomenon that has multiple important features that need to be addressed for the reduction of mortality rates due to COVID-19. Corticosteroids, such as hydrocortisone, dexamethasone, and methylprednisolone, have superior antiinflammatory, antifibrotic, and vasoconstrictive effects used for decreasing the host inflammatory reactions in the lungs, which may lead to acute lung injury and ARDS. Corticosteroids are associated with risks including delayed viral clearance from the respiratory tract and blood, risk of secondary infections, and elevated rates of difficulties such as avascular necrosis, psychosis, and hyperglycemia, although their usefulness overshadows the risk of negative side-effects. Corticosteroids have been used in a few surveys of SARS-CoV-1 and MERS infections. ${ }^{192-200}$

\section{Receptors targeted by glucocorticosteroids}

Glucocorticosteroids diffuse rapidly through the cell membrane and bind the ligand-binding domain of their cytoplasmic receptor, i.e., glucocorticoid receptors (GR), nuclear receptor subfamily 
Table 4. Repurposed antiviral drugs and their effects on SARS-CoV-2.

\begin{tabular}{|c|c|c|}
\hline Antiviral drugs & Effects & References \\
\hline Remdesivir (GS-5734) & $\begin{array}{l}\text { The broad-spectrum antiviral is a nucleotide analogue prodrug. RdRp effectively incorporates the } \\
\text { active triphosphate form of Remdesivir into RNA causing premature termination. Remdesivir } \\
\text { inhibit replication of other human coronaviruses including SARS-CoV in } 2003 \text { and MERS-CoV in } \\
\text { 2012. Promising therapeutic candidate for COVID-19. }\end{array}$ & 191 \\
\hline Favipiravir (T-705) & $\begin{array}{l}\text { Prodrug of a purine nucleotide, favipiravir ribofuranosyl-5 -triphosphate. Purine nucleotide } \\
\text { substrate for the RdRp and gets incorporated into the viral RNA strand preventing its further } \\
\text { extension and ultimately inhibiting its activity. Broad-spectrum activity. Modification of the } \\
\text { pyrazine moiety of T-1105, derivatives found to have antiviral activities. }\end{array}$ & 192,193 \\
\hline Lopinavir and ritonavir & $\begin{array}{l}\text { The formulation has been proved to be efficient against SARS-CoV and MERS-CoV infections. Inhibits } \\
\text { 3CLpro main protease. Ritonavir enhanced half-life and antiviral activity. }\end{array}$ & 192 \\
\hline
\end{tabular}

3 group C, member 1 (NR3C1), to induce activation. Once activated, GR translocates into the nucleus where it interacts with transcriptional coactivators or repressors to repress inflammatory genes or enhance the expression of anti-inflammatory genes. ${ }^{201,202}$ GR exists in all cells within the airway as the predominant GR $\alpha$ form. Other forms exist as the GR $\beta$ isoform, which acts as a dominant-negative regulator of $\mathrm{GR} \alpha$. The function of GR $\alpha$ is affected by post-translational modifications, with phosphorylation being the most studied. Ser211 phosphorylation has been linked to alterations in ligand binding, nuclear translocation, transactivation, and co-factor association. GR Ser226 phosphorylation, in contrast, is associated with greater transcriptional efficacy and can also be acetylated on K494 and K495 following activation (Ito et al. 2006b), affecting the ability of GR to interact with p65, and removal of these tags is important for the suppression of subsets of inflammatory genes. Small ubiquitinlike modifier (SUMO) proteins can also modify GRs and affect their functions. Sumoylation affects GR transactivation potential, particularly at promoters with multiple glucocorticoid response elements (GREs), whereas K293 GR sumoylation is essential for GC-induced evolutionary conserved inverted repeated negative GC response element-mediated direct transrepression and NF- $\mathrm{KB} / \mathrm{AP1}$-mediated $\mathrm{GC}$-induced tethered indirect transrepression in vitro. Nuclear GR can induce gene expression following DNA binding at specific GREs or, acting as a monomer, interacts with DNA-bound pro-inflammatory factors, thereby enabling transcriptional regulator proteins to be positioned such that they repress activated gene expression. Pro-inflammatory transcription factors such as AP-1 and NF- $\kappa$ B are the major targets for this tethering process although recent ChIP-seq analysis in airway epithelial cells indicates that tethering between GR and p65 for example is not essential for repression. ${ }^{203,204}$ Various trails are going on for patients with severe COVID-19. Trial Id PER-002 - a multicenter, adaptive, randomized, double-blinded, placebo-controlled Phase II/III trial to evaluate the efficacy and safety of monoclonal antibody SCTA01 against SARS-CoV-2 in hospitalized patients with severe COVID-19. ${ }^{205}$ Trial Id PER-008-21 - a Phase III randomized, double-blind, placebo-controlled, multicenter study to determine the safety and efficacy of AZD7442 for the treatment of COVID-19 in non-hospitalized adults. ${ }^{206}$ Trial Id ACTRN12621001543875 - Queensland COVID-19 vaccination (QoVAX) safety and efficacy trial pilot study in adults aged 18 years and over. ${ }^{207}$ Trial Id EUCTR 2021-005226-26-E A - Phase II study to evaluate safety and immunogenicity of recombinant protein candidate vaccine against SARS-CoV-2 in adults fully vaccinated against COVID-19. ${ }^{208}$ Trial Id CTRI/2021/10/037605 — effect of adjuvant yoga therapy on cardiorespiratory morbidity in COVID-19. ${ }^{209}$

\section{Side effects of corticosteroids}

Increased use of systemic corticosteroids may increase the risk of reactivation of quiescent infections, such as hepatitis B virus (HBV), herpesvirus infections, strongyloidiasis, and tuberculosis.
The surging sign of mucormycosis cases is correlated with preexisting medical ailments such as diabetes and surplus steroid use, which is why integrating the two factors is all the more hazardous. If a diabetic patient with COVID-19 is assigned steroids, they must regulate their blood sugar levels regularly. ${ }^{210}$ Indari et al. reported the inefficiency of dexamethasone in treating Plasmodium and SARS-CoV-2 co-infection, therefore needing further research for an effective steroid. ${ }^{211}$ Moderate to high dose use of glucocorticoids, in turn, poses a substantial risk of infections, encompassing common mild infections and significant life-threatening infections. It has been observed that with a high dose and period of medication, the threat increases linearly, particularly for widespread bacterial, viral, and fungal pathogens. Thus, unreasonable and imprudent use of corticosteroids in patients with diabetes is speculated to be responsible for the maximum accumulation of ROCM. The use of medium-high dose glucocorticoids for an extended period may lead to unexpected atherosclerosis in a dose-dependent manner. It can direct fluid retention, edema, weight gain, hypertension, and arrhythmias by increasing the renal excretion of potassium, calcium, and phosphate. Hypertension usually occurs with higher doses only, and other unfavorable effects can arise even with a low dose of glucocorticoids. These adverse effects include ecchymosis, skin thinning and atrophy, acne, mild hirsutism, facial erythema, stria, impaired wound healing, hair thinning, and perioral dermatitis. Glucocorticoid-induced osteoporosis is a well-known and destructive effect of long-term glucocorticoid use. Up to $40 \%$ of patients on long-term glucocorticoids experience bone loss, leading to fractures. With high-dose and long-term use of glucocorticoids, reversible painless steroid-induced myopathy, which is an explicit result of muscle breakdown, can occur in both upper and lower extremities. Long-term use of prednisone at $>20 \mathrm{mg}$ daily can lead to osteonecrosis, and patients with SLE and children are at increased risk. Systemic glucocorticoids induce a dose-dependent increase in fasting glucose levels and a more significant increase in postprandial values in patients without preexisting diabetes mellitus; however, the advancement of de novo diabetes in patients with initially normal glucose tolerance is unusual. Taking steroids at an initial stage of the disease can promote the replication of the virus, high doses of steroids in mild cases, on the other hand, may lead to severe viral pneumonia. Steroids should also be avoided during the first five days of infection. The synthetic steroids induce a persistent inhibition of the HPA axis, even after a duration of therapy, which is not understood because of the high inter-individual variability in pharmacokinetics and GR sensitivity. ${ }^{212}$ Further, the pathological modifications in cortisol metabolism and action in critically ill patients result in less cortisol degradation, varied binding protein levels, and accordingly, long-term adrenocorticotropic hormone and corticotropin (ACTH) suppression causing atrophy 
of the adrenal glands. Abrupt termination or abrupt withdrawal of glucocorticoids in such sufferers may cause indications of adrenal deficiency. Detailed scrutiny should be given to the consecutive phases of adrenal insufficiency whenever synthetic steroids are withdrawn. Adrenal deficiency is even more plausible in remedial schemes, including ritonavir (RTV), an antiviral drug that is also a competent inhibitor of cytochrome P450 3A4 (CYP3A4). By enhancing the concentrations of the additional drugs metabolized by a similar course, such as corticosteroids, this protease inhibitor can facilitate iatrogenic hypercortisolemia, which sequentially governs the poor synthesis and release of corticotropin-releasing hormone $(\mathrm{CRH})$ and $\mathrm{ACTH}$, facilitating a resultant hypocortisolemia state. It is usually at "supra-physiologic" quantities of corticosteroid administration where multiple and particularly drastic antagonistic effects of glucocorticoids occur, varying from mild suppression of the HPA axis to hazardous, life-threatening illnesses. Some unfavourable effects follow a linear dose-response pattern, where the incidence increases with an increase in dose (ecchymosis, cushingoid features, parchment-like skin, leg edema, and sleep disturbance). Gonorrhea medication can affect symptoms of hypercortisolism, primarily in patients with individual hypersensitivity or hypoadrenalism after HPA axis suppression, with outcomes in terms of heightened morbidity and mortality danger. ${ }^{213}$

Additionally, in SARS-CoV-2 infected patients, cortisol secretion could be insufficient due to significant illness-related corticosteroids. Accordingly, the abrupt discontinuation of a systemic steroid, specifically when related to RTV+ 1 variant immunodeficiency, could be hazardous. At the same time, the lasting side effects of additional medications, such as hydroxychloroquine (i.e., hypoglycemia) and antiviral drugs (i.e., diarrhea), could disguise a new fall in the hypocortisolemia state, which in turn would immediately impose adrenal replacement therapy. In addition, owing to the high homology with the structure of the original SARS-CoV, antibodies generated against SARS-CoV-2 have been deduced to cross-react with the ACTH peptide, potentially stimulating a comparable cortisol insufficiency. More specifically, adrenal insufficiency is related to a crucial reduction in the natural killer cell procedure that would, in turn, harm the recognition and elimination of virally infected cells. Thereafter, hypocortisolemia patients should be scrutinized for apparent healing of the infectious state; however, despite this, the novel developed antiviral immune shortcoming could be associated with increased mortality in respiratory infections such as COVID-19. The use of immunosuppressive drugs can lead to life-threatening opportunistic infections in patients with COVID-19, and the absence of considerable evidence for many of these therapies calls for a serious reassessment of recent therapeutic approaches for COVID-19, including monitoring for opportunistic fungal infections. The justification and advantage of allocating steroids in patients with COVID-19 require continual reappraisal to prevent the increasing number of iatrogenic casualties associated with steroid overuse in patients with SARS-CoV-2 infection. ${ }^{214}$ However, prolonged courses of steroids should not be given unless further conclusive evidence is available because steroids suppress the immune system, making the patient more susceptible to secondary infections. A rapid and aggressive COVID-19 treatment approach with the judicious use of steroids could be the best possible outcome and solution.

\section{Alternatives to corticosteroids}

Various additional antiviral agents, immunotherapies, and vaccines are being analyzed and formulated as conceivable therapies. Studying beneficial therapies for COVID-19 infection is a complex process. Approaches and studies of pharmacotherapy for COVID-19 have been published, but how these potential COVID19 therapies will decipher the mortal objective and usefulness is not skillfully or promptly comprehended. ${ }^{215}$ The question of whether or not prevailing medications that have shown in vitro antiviral activity might accomplish sufficient plasma pharmacokinetics with presently authorized doses was examined by Arshad et al. The research accordingly observed in vitro antiSARS-CoV-2 activity data from all accessible publications up to 13 April 2020 and recalculated the EC90 value for each drug. EC90 values were then reflected as a ratio to the feasible maximum plasma concentration $\left(C_{\max }\right)$ documented for each drug after administration of the approved dose to humans $\left(C_{\max }\right)$ EC90 ratio). The analysis also evaluated the unbound drug-totissue partition coefficient to anticipate lung concentrations that would surpass their documented EC50. ${ }^{216}$ Some immunomodulators are being promptly evaluated, primarily by repurposing existing drugs, to blunt the hyperinflammation caused by cytokine release. IL inhibitors and Janus kinase inhibitors (JAK) are just a few of the drugs that are in clinical trials.

Successive immune activation post-infection causes changes in the equilibrium of acute-phase reactants in the peripheral system. In the case of SARS-CoV-2 infection, higher levels of D-dimer, C-reactive protein (CRP), and procalcitonin (PCT) were associated with severe disease compared with non-severe disease. Adaptive immune response plays a significant role in regulating the spread of infection in the body. After the first week of symptom onset, virusspecific IgM isotype antibodies were identified in the patients. ${ }^{217}$

IL inhibitors may greatly alleviate the destruction of lung tissue caused by cytokine release in patients with critical COVID-19 infections. Numerous surveys have suggested a "cytokine storm" with the release of IL-6, IL-1, IL-12, and IL-8, along with tumour necrosis factor-alpha (TNF $\alpha$ ) and other inflammatory mediators, leading to a heightened pulmonary inflammatory reaction, which may raise the alveolar-capillary gas exchange, giving rise to oxygenation difficulties in patients with severe ailments.

Tocilizumab and baricitinib (JAK and NAK inhibitors) were issued emergency use authorizations (EUAs) on 24 June 2021 and 19 November 2020 for hospitalized grown-ups and pediatric patients (aged 2 years and older) with COVID-19 who were receiving systemic corticosteroids and needed additional oxygen, noninvasive or invasive automated ventilation, or extracorporeal membrane oxygenation (ECMO). ${ }^{218}$

Actemra is a monoclonal antibody (tocilizumab) that decreases inflammation by obstructing the IL-6 receptor. In the case of COVID-19 infection, the immune system can become hyperactive, leading to worsening of the disease. Actemra is a drug administered intravenously and approved by the FDA for multiple inflammatory diseases. The FDA has approved the emergency use of Actemra for the treatment of hospitalized patients with COVID-19, although Actemra is not authorized as a treatment for COVID-19. ${ }^{219}$

Anakinra is a recombinant human IL-1 receptor antagonist. There is an inadequate indication to approve or oppose the use of IL-1 inhibitors, such as anakinra, for the treatment of COVID-19.

The Numb-associated kinase (NAK) family has been associated with vast cellular purposes, including receptor-mediated endocytosis, osteoblast differentiation, dendritic morphogenesis, and cell-to-cell signaling and are potential drug targets owing to their wide-ranging purposes. Drugs that target NAK in patients with COVID-19 pneumonia when host inflammatory responses evolve as a primary factor of lung injury leading to mortality are very significant because they impede important cytokine signalling implicated in the immune-mediated inflammatory response. NAK inhibition has been shown to reduce viral infections in vitro. ACE2 receptors are a juncture of cellular passage by COVID-19, which is reflected in lung alveolar epithelial type II cells (AT2). AP2-associated protein kinase-1 (AAK1) is known to control endocytosis. The ability to disrupt AAK1 may halt the intracellular access of the virus. Fedratinib and ruxolitiniba JAK inhibitors are influential antiinflammatory agents that, as JAK-STAT signalling inhibitors, are valuable against the outcomes of the high levels of cytokines (including interferon- $\gamma$ ) typically identified in patients with COVID-19. ${ }^{218}$ 
Table 5. List of monoclonal antibodies against GM-CSF in COVID-19.

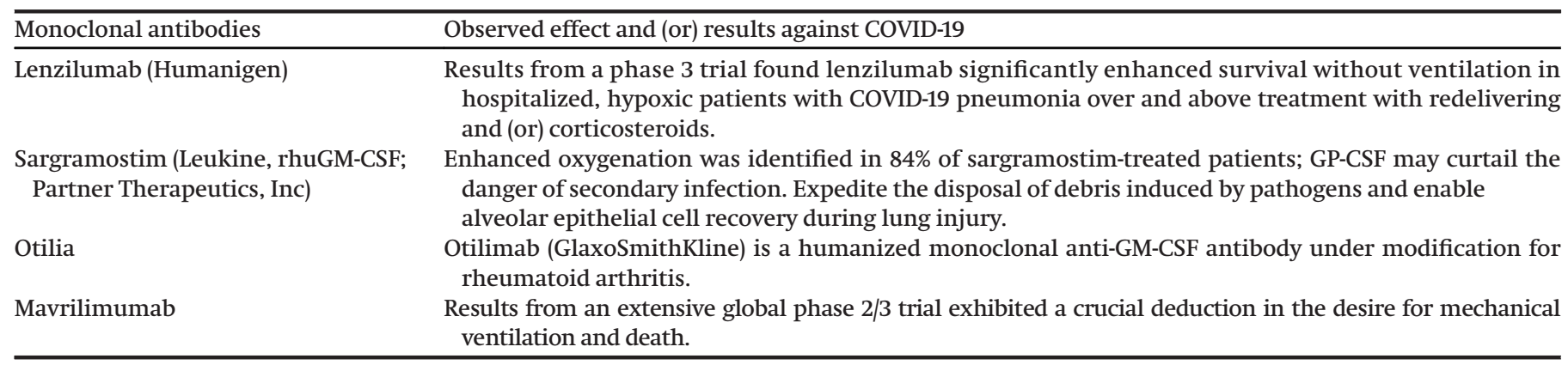

An additional investigational drug for ARDS/cytokine release of human vasoactive intestinal polypeptides is aviptadil (Zyesami; RLF-100; NeuroRx), an artificial vasoactive intestinal peptide (VIP) that impedes NMDA-induced caspase-3 activation in lungs and inhibits IL-6 and TNF-alpha generation. An EUA was submitted to the FDA on 1 June 2021 to treat critically sick patients with COVID19 and respiratory failure. Although antiviral therapy has shown benefits in dealing with patients with initial stages of COVID-19, it is early to ascertain improved comeback and survival in sufferers who have already advanced to respiratory failure. ${ }^{220}$ Alveolar type II (ATII) cells are susceptible because of their ACE2 surface receptors, which act as the path of entry for the infection. Aviptadil, binding specifically to the ATII in the air sac (alveolus) of the lung, has been shown to have potent anti-inflammatory/anti-cytokine action. Aviptadil is being surveyed as part of the NIH's ACTIV-3 critical care protocol independently and in combination with redelivery in hospitalized patients with ARDS. It is being reviewed as an inhaled therapy.

The spread induced by viral pathogens can also be managed by proteins extracted from alga shown in a study. Cyanovirin-N, an antiviral protein, inhibits cell-to-cell fusion, prevents HIV transmission, and alters viral binding to target cells by binding to glycoprotein gp120. It is the first biochemical constituent that reduces the invasion of the Ebola virus strain. Scytovirin, on the other hand, is known to hinder the aggression and proliferation of HIV and is derived from the water extract of Scytonema varium, a terrestrial cyanobacterium. ${ }^{221}$

In addition, natural active compounds in plants can be potential therapeutics for COVID-19. Nolide D and ferin A could be effective against the SARS-CoV-2 spike protein. ${ }^{222}$

The vast collection of genes elicited by interferons restricts the risk of antiviral resistance and makes interferons optimal agents for novel viral pathogens. Interferon lambdas, known as type III interferons, stimulate an antiviral state identical to that of interferon alpha or beta but use a diverse receptor complex with elevated expression levels restricted to epithelial cells in the lung, liver, and intestine, resulting in fewer systemic side effects. Interferon lambda- 1 restraints respiratory viral infections without the threat of stimulating cytokine storm syndrome, as has been observed in mice with type I interferon. Additionally, interferon lambda inhibits SARS-CoV-2 replication in cell culture and mouse models. Peginterferon lambda, a long-acting form of interferon lambda-1, has been examined in over 3000 patients with viral hepatitis infections, exhibiting antiviral potency similar to that of interferon alfa but with a preferable side-effect profile. ${ }^{223}$

Granulocyte-macrophage colony-stimulating factor (GM-CSF) is involved in the pathogenesis of respiratory failure in patients with drastic COVID-19 pneumonia and systemic hyperinflammation. ${ }^{226}$ A list of monoclonal antibodies against GM-CSF is provided in Table 5 and summarizes their observed effect in COVID-19 patients.

Foralumab intranasal - Tiziana Life Sciences, UK, has documented data from a small clinical trial of a nasally administered antibody in COVID-19 patients and observed that foralumab is an exception after assessing its ability to act on systemic immunity via the epithelial lining of the nose, leading it to trial a nasal formulation in healthy volunteers before the pandemic. Fully human anti-CD3 second-generation monoclonal antibody (mAb) Foralumab is dosed orally or nasally, organized into two heavy chains that modulate $\mathrm{T}$ cells and enhance regulatory $\mathrm{T}$ cells, resulting in an IL-10 anti-inflammatory indication. Bucillamine, an antirheumatic agent that arises from tiopronin, is another investigational immunotherapy (Revive Therapeutics). N-Acetyl cysteine (NAC) can considerably attenuate clinical warnings in respiratory viral diseases in animals and humans, mainly via the donation of thiols to enhance the antioxidant action of cellular glutathione. It has been shown to restore glutathione stores and enhance the proliferative response of T cells. Bucillamine has two thiol groups, and its capacity as a thiol donor was computed to be 16 times that of NAC. Antibodies granted for emergency uses such as Sotrovimab (VIR-7831; VIR Biotechnology; GlaxoSmithKline), which is a mAb that binds to a conserved epitope of the spiked protein of SARS-CoV-1 and SARS-CoV-2, thereby indicating the unlikelihood of mutational escape. This is supported by a preclinical trial showing its retained ability to neutralize SARS-CoV-2 variants ( B.1.1.7, B.1.351, and P.1). ${ }^{224}$

Casirivimab plus imdevimab was issued for intravenous coadministration of the monoclonal antibodies basiliximab and imdevimab (REGN-COV; Regeneron) on 21 November 2020 for the treatment of mild-to-moderate COVID-19. Similarly, bamlanivimab (LY-CoV555; Eli Lilly \& Co, AbCellera) neutralizes the IgG1mAb directed against the spike protein of SARS-CoV-2. It is designed to block viral attachment and entry into human cells, thereby neutralizing the virus and potentially preventing and treating COVID19. However, it is no longer recommended as a monotherapy owing to viral variants that are resistant to bamlanivimab. ${ }^{225}$

\section{Regulation of sex hormone after COVID-19}

Compared to men, women are less susceptible to viral infections based on differences in innate immunity, steroid hormones, and factors related to sex chromosomes (coronavirus COVID-19/SARS-CoV-2 affects women less than men: clinical response to viral infection). Sex hormones play an important role in the immune response, with estrogen seen as an immune booster and testosterone seen as an immunosuppressor. Additionally, an important protease involved in viral entry, TMPRSS2, is regulated by androgens. ${ }^{226}$ Estrogen has subtypes, making it difficult to assess its role as a single common regulatory hormone parameter for the SARS-CoV-2 pandemic, which affects all age groups and sexes. ${ }^{227}$ The finding that Ang II activates the NF- $\kappa$ B pathway to increase cytokine synthesis after SARS infection, while estrogen can shut down the NF-kB pathway, holds possible relevance for COVID-19 treatment strategies in female patients. ${ }^{228}$ A study showed that one-fifth of patients in the COVID-19 study exhibited a menstrual volume decrease or cycle prolongation, suggesting that they may be experiencing transient changes in sex hormone levels. The average sex hormone concentrations 
and ovarian reserve did not change significantly in women of childbearing age. ${ }^{229}$ Researchers have looked for the role of testosterone in COVID-19 patients with two upcoming theories: one suggesting low levels of testosterone and the other indicating high levels of testosterone as aggravating the course of COVID$19 .^{230}$ One study observed a higher serum LH and a lower T:LH ratio in the COVID-19 group. Multiple regression analysis indicated that the serum T:LH ratio was negatively associated with white blood cell counts and CRP levels in COVID-19 patients. ${ }^{142}$ A study by Shah et al. concluded that progesterone could contribute to antiviral activity against SARS-CoV-2, interference with the binding of SARS-CoV-2 to ACE2, recovery from pathogenesis, reduction in viral load, immune regulation, and hastened recovery from COVID-19. ${ }^{231}$

\section{COVID-19 vaccination}

COVID-19 vaccination is a critical component of prevention plans for the worldwide pandemic. Despite a few exceptional cases of adverse effects, the risk-benefit analysis for COVID-19 vaccination shows a strong positive balance in favor of vaccinations for all participants for whom vaccines have been licensed, regardless of age or gender. ${ }^{232}$ People who had COVID-19 had severe side effects after the first dose of the vaccine, but those who were not infected by the virus had worse side effects after the second dose of the vaccine, including tiredness, headache, muscular soreness, chills, fever, and nausea. More studies are needed to understand why these relationships occur. ${ }^{233}$ To properly manage vaccine side effects, they must be identified, tracked, and followed up on. The benefits of COVID-19 vaccination continue to outweigh any risk of adverse reactions. These concerns should not be used to support a change in vaccination policy, and further studies are required. ${ }^{232}$

\section{Conclusions}

We conclude that COVID-19 has several post-infection complications that have long-term damaging effects on organs, such as the lungs, kidneys, heart, skin, and neurons. The adverse effects of COVID-19 may increase due to coinfection with other pathogens, such as mucor. SARS-CoV-2 may impair phagocytic immune cell responses against the fungus through viral-induced lymphopenia or the therapeutic use of corticosteroids, which is the major defense mechanism against mucormycosis. Hence, it is important to have sound knowledge of drugs and their consequences. In this review, we discuss the history of SARS-CoV-2, post-COVID-19 complications, and organ damage. We have also provided updated information about the therapeutics, adjunctive therapeutics, and corticosteroids used against COVID-19. Long-term use of corticosteroids is known to have severe aftereffects. We have briefly discussed its side effects, the receptors it targets, and alternative drugs that can be used to treat COVID-19. Furthermore, we have included information about drugs against ARDS and investigational immunotherapies used against COVID-19. Furthermore, we have also included information about antibodies that have been granted authorization for emergency use. We believe that corticosteroids are key therapeutics against COVID-19. However, a thorough knowledge of its receptors and side effects would aid us in providing accurate information on its usage and when an alternative can be used. Hence, we have provided comprehensive information about post-COVID-19 complications, therapeutics explored, adjunct therapeutics used for COVID-19 management, and other investigational immunotherapies for COVID-19. Discussed complications can be single or in combination in the person, which may lead to health problems for different lengths of time. The goal of this review was not only to acquaint the researcher on the abovementioned topics, but also to further indicate and emphasize the systematic management and control of the disease to increase awareness and save us from entering another epidemic situation in the future.

\section{Acknowledgements}

We are grateful to the Department of Science and Technology, New Delhi, India, for the Ramanujan fellowship grant No. SB/S2/ RIN-132/20/5. DST-EMR: EMR/2017/001637. Ms. Charu Sonkar thanks CSIR, India, for her doctoral fellowship (09/1022(0035)/2017-EMR-I). The authors are grateful to their parent institute for their support.

\section{References}

(1) Chen, J.; Lu, H. BioSci. Trends, 2021, 15 (2), 126. doi:10.5582/bst.2021.01092.

(2) Weekly epidemiological update on COVID-19 - 24 August 2021. Available from https://www.who.int/publications/m/item/weekly-epidemiologicalupdate-on-covid-19 - 24-august-2021 (Accessed 6 December 2021).

(3) Clinical spectrum of SARS-CoV-2 infection. Available from https:/ www.covid19treatmentguidelines.nih.gov/overview/clinical-spectrum/ (Accessed 29 August 2021).

(4) Nalbandian, A.; Sehgal, K.; Gupta, A.; Madhavan, M. V.; McGroder, C.; Stevens, J. S.; et al. Nat. Med. 2021, 27 (4), 601. doi:10.1038/s41591-021-01283-z.

(5) COVID-19 rapid guideline: managing the long-term effects of COVID-19. NICE guideline[NG188]. Available from https://www.nice.org.uk/guidance/ ng188 (Accessed 29 August 29).

(6) Andersen, K. G.; Rambaut, A.; Lipkin, W. I.; Holmes, E. C.; Garry, R. F. Nat. Med. 2020, 26 (4), 450. doi:10.1038/s41591-020-0820-9.

(7) Mustafa, M. I.; Abdelmoneim, A. H.; Mahmoud, E. M.; Makhawi, A. M. Mediators Inflamm. 2020, 2020, 8198963. doi:10.1155/2020/8198963.

(8) Ragab, D.; Salah Eldin, H.; Taeimah, M.; Khattab, R.; Salem, R. Front. Immunol. 2020, 11, 1446. doi:10.3389/fimmu.2020.01446.

(9) Honigsbaum, M.; Krishnan, L. Lancet, 2020, 396 (10260), 1389. doi:10.1016/ S0140-6736(20)32134-6.

(10) Cascella, M.; Rajnik, M.; Aleem, A.; Dulebohn, S. C.; Napoli, R. D. Features, evaluation, and treatment of coronavirus (COVID-19); StatPearls Publishing; 2021.

(11) del Rio, C.; Collins, L. F.; Malani, P. JAMA, 2020, 324 (17), 1723. doi:10.1001/ jama.2020.19719.

(12) Batawi, S.; Tarazan, N.; Al-Raddadi, R.; Al Qasim, E.; Sindi, A.; Al Johni, S.; et al. Health Qual. Life Outcomes, 2019, 17, 101. doi:10.1186/s12955-019-1165-2.

(13) Tansey, C. M.; Louie, M.; Loeb, M.; Gold, W. L.; Muller, M. P.; de Jager, J.-A.; et al. Arch. Intern. Med. 2007, 167 (12), 1312. doi:10.1001/archinte.167.12.1312.

(14) Zhang, P.; Li, J.; Liu, H.; Han, N.; Ju, J.; Kou, Y.; et al. Bone Res. 2020, 8, 8. doi:10.1038/s41413-020-0084-5.

(15) Yu, C. C. W.; Li, A. M.; So, R. C. H.; McManus, A.; Ng, P. C.; Chu, W.; et al. Thorax, 2006, 61 (3), 240. doi:10.1136/thx.2005.046854.

(16) White, J. Clin. Microbiol. Newsl. 2014, 36 (15), 115. doi:10.1016/j.clinmicnews. 2014.07.002.

(17) Wang, H.; Ding, Y.; Li, X.; Yang, L.; Zhang, W.; Kang, W. N. Engl. J. Med. 2003, 349 (5), 507. doi:10.1056/NEJM200307313490519.

(18) Song, G.; Liang, G.; Liu, W. Mycopathologia, 2020, 185, 599. doi:10.1007| s11046-020-00462-9.

(19) Elkholy, A. A.; Grant, R.; Assiri, A.; Elhakim, M.; Malik, M. R.; Van Kerkhove, M. D. J. Infect. Public Health, 2020, 13 (3), 418. doi:10.1016/ j.jiph.2019.04.011.

(20) O’Sullivan, O. Clin. Med. (Lond), 2021, 21 (1), e68. doi:10.7861/clinmed.20200204.

(21) Lau, H. M.-C.; Ng, G. Y.-F.; Jones, A. Y.-M.; Lee, E. W.-C.; Siu, E. H.-K.; Hui, D. S.-C. Aust. J. Physiother. 2005, 51 (4), 213. doi:10.1016/S0004-9514 (05)70002-7.

(22) Jakhmola, S.; Indari, O.; Kashyap, D.; Varshney, N.; Rani, A.; Sonkar, C.; et al. Heliyon, 2020, 6 (12), e05706. doi:10.1016/j.heliyon.2020.e05706.

(23) Gavriatopoulou, M.; Korompoki, E.; Fotiou, D.; Ntanasis-Stathopoulos, I.; Psaltopoulou, T.; Kastritis, E.; Terpos, E.; Dimopoulos, M.A. Clin. Exp. Med. 2020, 20 (4), 493. doi:10.1007/s10238-020-00648-X.

(24) Saeed, S.; Tadic, M.; Larsen, T. H.; Grassi, G.; Mancia, G. J. Hypertens. 2021, 39 (7), 1282. doi:10.1097/HJH.0000000000002819.

(25) Nambiar, M.; Varma, S. R.; Damdoum, M. Saudi J. Biol. Sci. 2021, 28 (11), 6461. doi:10.1016/j.sjbs.2021.07.004.

(26) Tenforde, M. W. MMWR Morb. Mortal Wkly. Rep. 2020, 69 (30), 993. doi:10.15585/mmwr.mm6930e1.

(27) Lopez-Leon, S.; Wegman-Ostrosky, T.; Perelman, C.; Sepulveda, R.; Rebolledo, P. A.; Cuapio, A.; Villapol, S. Sci. Rep. 2021, 11 (1), 16144. doi:10.1038/s41598-021-95565-8.

(28) Cheng, D.; Calderwood, C.; Skyllberg, E.; Ainley, A. BMJ Open Respir. Res. 2021, 8 (1), e000813. doi:10.1136/bmjresp-2020-000813.

(29) Mandal, S.; Barnett, J.; Brill, S. E.; Brown, J. S.; Denneny, E. K.; Hare, S. S.; et al. Thorax, 2021, 76 (4), 396. doi:10.1136/thoraxjnl-2020-215818.

(30) Bowles, K. H.; McDonald, M.; Barrón, Y.; Kennedy, E.; O’Connor, M.; Mikkelsen, M. Ann. Intern. Med. 2021, 174 (3), 316. doi:10.7326/M20-5206.

(31) Xiong, Q.; Xu, M.; Li, J.; Liu, Y.; Zhang, J.; Xu, Y.; Dong, W. Clin. Microbiol. Infect. 2021, 27 (1), 89. doi:10.1016/j.cmi.2020.09.023. 
(32) De Lorenzo, R.; Conte, C.; Lanzani, C.; Benedetti, F.; Roveri, L.; Mazza, M. G.; et al. PLoS One, 2020, 15 (10), e0239570. doi:10.1371/journal. pone.0239570.

(33) Boscolo-Rizzo, P.; Menegaldo, A.; Fabbris, C.; Spinato, G.; Borsetto, D.; Vaira, L. A.; et al. Chem. Senses, 2021, 46, bjab006. doi:10.1093/chemse/ bjab006.

(34) Silva, D. L.; Lima, C. M.; Magalhães, V. C. R.; Baltazar, L. M.; Peres, N. T. A.; Caligiorne, R. B.; et al. J. Hosp. Infect. 2021, 113, 145. doi:10.1016/j.jhin. 2021.04.001.

(35) Huang, L.; Zhao, P.; Tang, D.; Zhu, T.; Han, R.; Zhan, C.; et al. JACC Cardiovasc. Imaging, 2020, 13 (11), 2330. doi:10.1016/j.jcmg.2020.05.004.

(36) Ng, M.-Y.; Ferreira, V. M.; Leung, S. T.; Lee, J. C. Y.; Fong, A. H.-T.; Liu, R. W. T.; et al. JACC Cardiovasc. Imaging, 2020, 13 (11), 2476. doi:10.1016/ j.jcmg.2020.08.012.

(37) Guo, T.; Fan, Y.; Chen, M.; Wu, X.; Zhang, L.; He, T.; et al. JAMA Cardiol. 2020, 5 (7), 811. doi:10.1001/jamacardio.2020.1017.

(38) Małek, Ł. A.; Marczak, M.; Miłosz-Wieczorek, B.; Konopka, M.; Braksator, W.; Drygas, W.; Krzywański, J. J. Magn. Reson. Imaging, 2021, 53 (6), 1723. doi:10.1002/jmri.27513.

(39) Sonnweber, T.; Sahanic, S.; Pizzini, A.; Luger, A.; Schwabl, C.; Sonnweber, B.; et al. Eur. Respir. J. 2021, 57 (4), 2003481. doi:10.1183/ 13993003.03481-2020.

(40) Puntmann, V. O.; Carerj, M. L.; Wieters, I.; Fahim, M.; Arendt, C.; Hoffmann, J.; et al. JAMA Cardiol. 2020, 5 (11), 1265. doi:10.1001/ jamacardio.2020.3557.

(41) Blanco, J.-R.; Cobos-Ceballos, M.-J.; Navarro, F.; Sanjoaquin, I.; Arnaiz de Las Revillas, F.; Bernal, E.; et al. Clin. Microbiol. Infect. 2021, 27 (6), 892. doi:10.1016/j.cmi.2021.02.019.

(42) Sigfrid, L.; Drake, T. M.; Pauley, E.; Jesudason, E. C.; Olliaro, P.; Lim, W. S.; et al.; ISARIC4C investigators. Lancet Reg. Health Eur. 2021, 8, 100186. doi:10.1016/j.lanepe.2021.100186.

(43) Moreno-Pérez, O.; Merino, E.; Leon-Ramirez, J.-M.; Andres, M.; Ramos, J. M.; Arenas-Jiménez, J. et al.; COVID19-ALC research group. J. Infect. 2021, 82 (3), 378. doi:10.1016/j.jinf.2021.01.004.

(44) Kumar, M. A.; Krishnaswamy, M.; Arul, J. N. BMJ Case Rep. 2021, 14 (1), e241059. doi:10.1136/bcr-2020-241059.

(45) Sajal, D.; Mudalsha, R.; Tinu, L.; Ranganath, T. G.; Dibakar, S. J. Nucl. Med. Technol. 2021, 49 (4), 320. doi:10.2967/jnmt.121.262440.

(46) Lim, S. T.; Janaway, B.; Costello, H.; Trip, A.; Price, G. BJPsych Open, 2020, 6 (5), e105. doi:10.1192/bjo.2020.76.

(47) Parpas, A.; Yudd, M.; Dreisbach, A. W.; Michaud, J. Ren. Fail. 2021, 43 (1), 530. doi:10.1080/0886022X.2021.1895839.

(48) Hohberger, B.; Ganslmayer, M.; Lucio, M.; Kruse, F.; Hoffmanns, J.; Moritz, M.; et al. Front Med. (Lausanne), 2021, 8, 676554. doi:10.3389/ fmed.2021.676554. PMID:34307408.

(49) Nugent, J.; Aklilu, A.; Yamamoto, Y.; Simonov, M.; Li, F.; Biswas, A.; et al. JAMA Netw. Open, 2021, 4 (3), e211095. doi:10.1001/jamanetworkopen.2021.1095.

(50) Nahi, S. L.; Shetty, A. A.; Tanna, S. D.; Leventhal, J. R. PLoS One, 2021, 16 (6), e0252979. doi:10.1371/journal.pone.0252979.

(51) Taquet, M.; Geddes, J. R.; Husain, M.; Luciano, S.; Harrison, P. J. Lancet Psychiatry, 2021, 8 (5), 416. doi:10.1016/S2215-0366(21)00084-5.

(52) Durazo, F. A.; Nicholas, A. A.; Mahaffey, J. J.; Sova, S.; Evans, J. J.; Trivella, J. P.; et al. Transplant. Proc. 2021, 53 (4), 1132. doi:10.1016/j. transproceed.2021.03.007.

(53) Roth, N. C.; Kim, A.; Vitkovski, T.; Xia, J.; Ramirez, G.; Bernstein, D.; Crawford, J. M. Am. J. Gastroenterol. 2021, 116 (5), 1077. doi:10.14309/ ajg.0000000000001154

(54) Weng, J.; Li, Y.; Li, J.; Shen, L.; Zhu, L.; Liang, Y.; et al. Lancet Gastroenterol. Hepatol. 2021, 6 (5), 344. doi:10.1016/S2468-1253(21)00076-5.

(55) Linschoten, M.; Peters, S.; van Smeden, M.; Jewbali, L. S.; Schaap, J.; Siebelink, H.-M.; et al.; CAPACITY-COVID collaborative consortium. Eur. Heart J. Acute Cardiovasc. Care, 2020, 9 (8), 817. doi:10.1177/2048872620974605.

(56) Khedr, E. M.; Shoyb, A.; Mohammaden, M.; Saber, M. Epilepsy Res. 2021, 174, 106650. doi:10.1016/j.eplepsyres.2021.106650.

(57) Romero-Duarte, Á.; Rivera-Izquierdo, M.; Guerrero-Fernández de Alba, I.; Pérez-Contreras, M.; Fernández-Martínez, N. F.; Ruiz-Montero, R. BMC Med. 2021, 19 (1), 129. doi:10.1186/s12916-021-02003-7.

(58) Vila-Candel, R.; Mena-Tudela, D.; Gómez-Seguí, A.; Asensio-Tomás, N.; Cervera-Gasch, A.; Herraiz-Soler, Y. Enferm. Clin. (Engl. Ed.), 2021, 31 (3), 184. doi:10.1016/j.enfcli.2021.01.006.

(59) Shouman, K.; Vanichkachorn, G.; Cheshire, W. P.; Suarez, M. D.; Shelly, S.; Lamotte, G. J.; et al. Clin. Auton. Res. 2021, 31 (3), 385. doi:10.1007/ s10286-021-00803-8.

(60) Velayos, M.; Muñoz-Serrano, A. J.; Estefanía-Fernández, K.; Sarmiento Caldas, M. C.; Moratilla Lapeña, L.; López-Santamaría, M.; López-Gutiérrez, J. C. An. Pediatr. (Engl. Ed.), 2020, 93 (2), 118. doi:10.1016/j.anpedi.2020.04.022.

(61) Guedj, E.; Campion, J. Y.; Dudouet, P.; Kaphan, E.; Bregeon, F.; Tissot-Dupont, H.; et al. Eur. J. Nucl. Med. Mol. Imaging, 2021, 48 (9), 2823. doi:10.1007/s00259-021-05215-4.

(62) Medrinal, C.; Prieur, G.; Bonnevie, T.; Gravier, F.-E.; Mayard, D; Desmalles, E.; et al. BMC Anesthesiol. 2021, 21 (1), 64. doi:10.1186/s12871021-01274-0.

(63) Naous, E.; Nassani, B.-M.; Yaghi, C.; Nasr, F.; Medlej, R. J. Hematop. 2021, 14, 229. doi:10.1007/s12308-021-00452-w.
(64) Aguilar-Gamboa, F. R.; Cubas-Alarcon, D.; Villegas-Chiroque, M.; Failoc-Rojas, V. E. Colomb. Med. (Cali), 2021, 52 (1), e7014577. doi:10.25100/ cm.v52i1.4577. PMID:33911322.

(65) Fineschi, S. Front Immunol. 2021, 12, 686699. doi:10.3389/fimmu.2021. 686699.

(66) Jalalzadeh, M.; Valencia-Manrique, J. C.; Boma, N.; Chaudhari, A.; Chaudhari, S. Cureus, 2021, 13 (1), e12485. doi:10.7759/cureus.12485.

(67) Rizzetto, G.; Diotallevi, F.; Campanati, A.; Radi, G.; Bianchelli, T.; Molinelli, E.; Mazzanti, S.; Offidani, A. Dermatol. Ther. 2021, 34 (1), e14547. doi:10.1111/dth.14547. PMID:33190397.

(68) Singh, A. K.; Misra, A. Diabetes Metab. Syndr. 2020, 14 (6), 1625. doi:10.1016/j. dsx.2020.08.032.

(69) Parry, Z. A.; Bumb, S. S.; Kumar, S.; Bhatt, R.; Irfan, M.; Bhatt, P. Bangladesh J. Med. Sci. 2021, 20 (5), 155. doi:10.3329/bjms.v20i5.55414.

(70) Bhayana, S.; Kalra, M.; Sachdeva, P.; Sachdeva, A. Cancer Res. Stat. Treat. 2021, 4 (2), 262. doi:10.4103/crst.crst 98 21.

(71) Aggarwal, A.; Shrivastava, A.; Kumar, A.; Ali, A. J. Assoc. Physicians India, 2020, 68 (7), 19. PMID:32602676.

(72) Kumar, B.; Gopalakrishnan, M.; Garg, M. K.; Purohit, P.; Banerjee, M.; Sharma, P.; et al. Indian J. Endocrinol. Metab. 2021, 25 (1), 14. doi:10.4103/ ijem.IJEM_577_20. PMID:34386388.

(73) Varshney, M.; Parel, J. T.; Raizada, N.; Sarin, S. K. PLoS One, 2020, 15 (5), e0233874. doi:10.1371/journal.pone.0233874.

(74) Mohamed-Hussein, A. A. R.; Amin, M. T.; Makhlouf, H. A.; Makhlouf, N. A.; Galal, I.; Abd-Elaal, H. K.; et al. Int. J. Tuberc. Lung Dis. 2021, 25 (9), 732. doi:10.5588/ijtld.21.0135.

(75) Zhao, Y.-M.; Shang, Y.-M.; Song, W.-B.; Li, Q.-Q.; Xie, H.; Xu, Q.-F.; et al. EclinicalMedicine, 2020, 25, 100463. doi:10.1016/j.eclinm.2020.100463.

(76) Ceylan, K. C.; Batihan, G.; Yazgan, S.; Gürsoy, S.; Kıraklı, S. C.; Ataman, S. Eur. J. Cardiothorac. Surg. 2020, 58 (6), 1216. doi:10.1093/ejcts/ ezaa356.

(77) George, P. M.; Barratt, S. L.; Condliffe, R.; Desai, S. R.; Devaraj, A.; Forrest, I. . Thorax, 2020, 75 (11), 1009. doi:10.1136/thoraxjnl-2020-215314.

(78) Solomon, J. J.; Heyman, B.; Ko, J. P.; Condos, R.; Lynch, D. A. Radiology, 2021, 211396. doi:10.1148/radiol.2021211396.

(79) Udwadia, Z. F.; Koul, P. A.; Richeldi, L. Lung India, 2021, 38 (Suppl.), S41. doi:10.4103/lungindia.lungindia_818_20.

(80) Yang, Z. L.; Chen, C.; Huang, L.; Zhou, S. C.; Hu, Y. N.; Xia, L. M.; Li, Y. Front. Med. 2020, 7, 833. doi:10.3389/fmed.2020.605088.

(81) Basu-Ray, I.; Almaddah, N. K.; Adeboye, A.; Soos, M. P. Cardiac manifestations of coronavirus (COVID-19). StatPearls Publishing, Treasure Island, Fla. 2021.

(82) Lang, J. P.; Wang, X.; Moura, F. A.; Siddiqi, H. K.; Morrow, D. A.; Bohula, E. A. Am. Heart J. 2020, 226, 29. doi:10.1016/j.ahj.2020.04.025.

(83) Zhou, F.; Yu, T.; Du, R.; Fan, G.; Liu, Y.; Liu, Z.; et al. Lancet, 2020, 395 (10229), 1054. doi:10.1016/S0140-6736(20)30566-3.

(84) Sharma, K.; Desai, H. D.; Patoliya, J. V.; Jadeja, D. M.; Gadhiya, D. SN Compr. Clin. Med. 2021, 3, 62. doi:10.1007/s42399-021-00743-4.

(85) Wu, Y.; Xu, X.; Chen, Z.; Duan, J.; Hashimoto, K.; Yang, L.; Liu, C.; Yang, C. Brain Behav. Immun. 2020, 87, 18. doi:10.1016/j.bbi.2020.03.031.

(86) Beghi, E.; Feigin, V.; Caso, V.; Santalucia, P.; Logroscino, G. Neuroepidemiology, 2020, 54 (5), 364. doi:10.1159/000508991.

(87) Jakhmola, S.; Indari, O.; Chatterjee, S.; Jha, H. C. SN Compr. Clin. Med. 2020, 2, 2137. doi:10.1007/s42399-020-00522-7.

(88) Mao, L.; Jin, H.; Wang, M.; Hu, Y.; Chen, S.; He, Q.; et al. JAMA Neurol. 2020, 77 (6), 683. doi:10.1001/jamaneurol.2020.1127.

(89) Tsai, S.-T.; Lu, M.-K.; San, S.; Tsai, C.-H. Front Neurol. 2020, 11, 498. doi:10.3389/fneur.2020.00498. PMID:32574246.

(90) Goërtz, Y. M. J.; Van Herck, M.; Delbressine, J. M.; Vaes, A. W.; Meys, R.; Machado, F. V. C.; et al. ERJ Open Res. 2020, 6 (4), 00542. doi:10.1183/23120541.00542-2020.

(91) Zhu, N.; Zhang, D.; Wang, W.; Li, X.; Yang, B.; Song, J.; et al.; China Novel Coronavirus Investigating and Research Team. N. Engl. J. Med. 2020, 382 (8), 727. doi:10.1056/NEJMoa2001017.

(92) Mao, L.; Jin, H.; Wang, M.; Hu, Y.; Chen, S.; He, Q.; et al. JAMA Neurol. 2020, 77 (6), 683. doi:10.1001/jamaneurol.2020.1127.

(93) Jarrahi, A.; Ahluwalia, M.; Khodadadi, H.; da Silva Lopes Salles, E.; Kolhe, R.; Hess, D. C.; et al. J. Neuroinflamm. 2020, 17 (1), 286. doi:10.1186/ s12974-020-01957-4.

(94) Guan, W.-J.; Ni, Z.-Y.; Hu, Y.; Liang, W.-H.; Ou, C.-Q.; He, J.-X.; et al. N. Engl. J. Med. 2020, 382 (18), 1708. doi:10.1056/NEJMoa2002032.

(95) Søraas, A.; Bø, R.; Kalleberg, K. T.; Støer, N. C.; Ellingjord-Dale, M.; Landrø, N. I. JAMA Netw. Open, 2021, 4 (7), e2118717. doi:10.1001/ jamanetworkopen.2021.18717.

(96) Oh, E. S.; Vannorsdall, T. D.; Parker, A. M. JAMA Netw. Open, 2021, 4 (7), e2119335. doi:10.1001/jamanetworkopen.2021.19335.

(97) Camdessanche, J.-P.; Morel, J.; Pozzetto, B.; Paul, S.; Tholance, Y.; Botelho-Nevers, E. Rev. Neurol. (Paris), 2020, 176 (6), 516. doi:10.1016/j. neurol.2020.04.003.

(98) Khan, F.; Sharma, P.; Pandey, S.; Sharma, D.; V, V.; Kumar, N.; et al. J. Med. Virol. 2021, 93 (10), 6045. doi:10.1002/jmv.27159.

(99) Tveit, L.; Enriquez, B.; Tennøe, B.; Warsza, B.; Garstad, L. J.; Weisshaar, M.; Aamodt, A.H. Tidsskr. Nor. Laegeforen. 2020, 140 (18). doi:10.4045/tidsskr. 20.0563. 
(100) Hanafi, R.; Roger, P.-A.; Perin, B.; Kuchcinski, G.; Deleval, N.; Dallery, F.; et al. Am. J. Neuroradiol. 2020, 41 (8), 1384. doi:10.3174/ajnr.A6651.

(101) Varatharaj, A.; Thomas, N.; Ellul, M. A.; Davies, N. W. S.; Pollak, T. A.; Tenorio, E. L.; et al. Lancet Psychiatry, 2020, 7 (10), 875. doi:10.1016/S22150366(20)30287-X.

(102) Sotoca, J.; Rodríguez-Álvarez, Y. Neurol. Neuroimmunol. Neuroinflamm. 2020, 7 (5), e803. doi:10.1212/NXI.0000000000000803.

(103) Zubair, A. S.; McAlpine, L. S.; Gardin, T.; Farhadian, S.; Kuruvilla, D. E.; Spudich, S. JAMA Neurol. 2020, 77 (8), 1018. doi:10.1001/jamaneurol.2020.2065.

(104) Bitirgen, G.; Korkmaz, C.; Zamani, A.; Ozkagnici, A.; Zengin, N.; Ponirakis, G.; Malik, R. A. Br. J. Ophthalmol. 2021. [In press]. doi:10.1136/ bjophthalmol-2021-319450.

(105) Poyiadji, N.; Shahin, G.; Noujaim, D.; Stone, M.; Patel, S.; Griffith, B. Radiology, 2020, 296 (2), E119. doi:10.1148/radiol.2020201187.

(106) Parsons, T.; Banks, S.; Bae, C.; Gelber, J.; Alahmadi, H.; Tichauer, M. J. Neurol. 2020, 267 (10), 2799. doi:10.1007/s00415-020-09951-9.

(107) Reichard, R. R.; Kashani, K. B.; Boire, N. A.; Constantopoulos, E.; Guo, Y.; Lucchinetti, C. F. Acta Neuropathol. 2020, 140 (1), 1. doi:10.1007/ s00401-020-02166-2.

(108) Novi, G.; Rossi, T.; Pedemonte, E.; Saitta, L.; Rolla, C.; Roccatagliata, L.; Inglese, M.; Farinini, D. Neurol. Neuroimmunol. Neuroinflamm. 2020, 7 (5), e797. doi:10.1212/NXI.0000000000000797.

(109) Brann, D. H.; Tsukahara, T.; Weinreb, C.; Lipovsek, M.; Van den Berge, K.; Gong, B.; et al. Sci. Adv. 2020, 6 (31), eabc5801. doi:10.1126/sciadv.abc5801.

(110) Samaranayake, L. P.; Fakhruddin, K. S.; Panduwawala, C. Acta Odontol. Scand. 2020, 78 (6), 467. doi:10.1080/00016357.2020.1787505.

(111) Augustin, M.; Schommers, P.; Stecher, M.; Dewald, F.; Gieselmann, L.; Gruell, H.; et al. Lancet Reg. Health Eur. 2021, 6, 100122. doi:10.1016/j. lanepe.2021.100122.

(112) Favas, T. T.; Dev, P.; Chaurasia, R. N.; Chakravarty, K.; Mishra, R.; Joshi, D.; et al. Neurol. Sci. 2020, 41 (12), 3437. doi:10.1007/s10072-020-04801-y.

(113) Almufarrij, I.; Uus, K.; Munro, K. J. Int. J. Audiol. 2020, 59 (7), 487. doi:10.1080/14992027.2020.1776406.

(114) Saniasiaya, J. Ear. Nose Throat J. 2021, 100 (2 Suppl.), 152S. doi:10.1177/ 0145561320946902.

(115) Devilliers, M.-J.; Ben Hadj Salah, W.; Barreau, E.; Da Cunha, E.; M'Garrech, M.; Bénichou, J.; Labetoulle, M.; Rousseau, A. Rev. Med. Intern. 2021, 42 (6), 401. doi:10.1016/j.revmed.2020.08.022.

(116) Shah, K. K.; Venkatramani, D.; Majumder, P. D. Indian J. Ophthalmol. 2021, 69 (5), 1322. doi:10.4103/ijo.IJO_3755_20. PMID:33913891.

(117) Bertoli, F.; Veritti, D.; Danese, C.; Samassa, F.; Sarao, V.; Rassu, N.; Gambato, T.; Lanzetta, P. J. Ophthalmol. 2020, 2020, 4827304. doi:10.1155/2020/ 4827304.

(118) Marinho, P. M.; Marcos, A. A. A.; Romano, A. C.; Nascimento, H.; Belfort, R. Lancet, 2020, 395 (10237), 1610. doi:10.1016/S0140-6736(20)31014-X.

(119) Sheth, J. U.; Narayanan, R.; Goyal, J.; Goyal, V. Indian J. Ophthalmol. 2020, 68 (10), 2291. doi:10.4103/ijo.IJO_2380_20.

(120) Rao, D. S.; Nomier, Y. A.; Ahmed, R. A.; Noureldeen, A. N. J. Adv. Pharm. Technol. Res. 2021, 12 (2), 209. doi:10.4103/japtr.JAPTR_245_20.

(121) Galea, S.; Merchant, R. M.; Lurie, N. JAMA Intern. Med. 2020, 180 (6), 817. doi:10.1001/jamainternmed.2020.1562.

(122) Rogers, J. P.; Chesney, E.; Oliver, D.; Pollak, T. A.; McGuire, P.; Fusar-Poli, P.; et al. Lancet Psychiatry, 2020, 7 (7), 611. doi:10.1016/S2215-0366(20) 30203-0.

(123) Halpin, S. J.; McIvor, C.; Whyatt, G.; Adams, A.; Harvey, O.; McLean, L.; et al. J. Med. Virol. 2021, 93 (2), 1013. doi:10.1002/jmv.26368.

(124) Zhou, H.; Lu, S.; Chen, J.; Wei, N.; Wang, D.; Lyu, H.; Shi, C.; Hu, S. J. Psychiatr. Res. 2020, 129, 98. doi:10.1016/j.jpsychires.2020.06.022.

(125) Bo, H.-X.; Li, W.; Yang, Y.; Wang, Y.; Zhang, Q.; Cheung, T.; Wu, X.; Xiang, Y.-T. Psychol. Med. 2021, 51 (6), 1052. doi:10.1017/S0033291720000999.

(126) Vlake, J. H.; Wesselius, S.; van Genderen, M. E.; van Bommel, J.; Boxma-de Klerk, B.; Wils, E.-J. PLoS One, 2021, 16 (8), e0255774. doi:10.1371/ journal.pone.0255774.

(127) Mao, R.; Qiu, Y.; He, J.-S.; Tan, J.-Y.; Li, X.-H.; Liang, J.; et al. Lancet Gastroenterol. Hepatol. 2020, 5 (7), 667. doi:10.1016/S2468-1253(20)30126-6.

(128) Ong, J.; Young, B. E.; Ong, S. Gut, 2020, 69 (6), 1144. doi:10.1136/gutjnl2020-321051.

(129) Liang, W.; Feng, Z.; Rao, S.; Xiao, C.; Xue, X.; Lin, Z.; Zhang, Q.; Qi, W. Gut, 2020, 69 (6), 1141. doi:10.1136/gutjnl-2020-320832.

(130) Sonkar, C.; Kashyap, D.; Varshney, N.; Baral, B.; Jha, H. C. SN Compr. Clin. Med. 2020, 2, 2658. doi:10.1007/s42399-020-00619-z.

(131) Chai, X.; Hu, L.; Zhang, Y.; Han, W.; Lu, Z.; Ke, A., et al. 2020, 2020.02.03.931766. doi:10.1101/2020.02.03.931766

(132) Tang, L.; Gu, S.; Gong, Y.; Li, B.; Lu, H.; Li, Q.; et al. Engineering (Beijing), 2020, 6 (10), 1178. doi:10.1016/j.eng.2020.05.013. PMID:33520333.

(133) Memari, A.; Shariat, A.; Anastasio, A. T. Work, 2020, 66 (4), 751. doi:10.3233/ WOR-203221.

(134) Akbarialiabad, H.; Taghrir, M. H.; Abdollahi, A.; Ghahramani, N.; Kumar, M.; Paydar, S.; et al. Infection, 2021, 49, 1163. doi:10.1007/s15010021-01666-X.

(135) Agarwala, S. R.; Vijayvargiya, M.; Pandey, P. BMJ Case Rep. 2021, 14 (7), e242101. doi:10.1136/bcr-2021-242101.

(136) Chan, K. L.; Mok, C. C. Open Orthop. J. 2012, 6, 449. doi:10.2174/ 1874325001206010449.
(137) Chen, L.; Wang, B.-Z.; Xie, J.; Jin, C.; Chen, W.-K.; Fang, K.-H.; et al. Free Radic. Biol. Med. 2021, 176, 228. doi:10.1016/j.freeradbiomed.2021.07.016.

(138) Kamath, S. D.; Sharma, B.; Laik, J. K.; Kumar, M.; Sunder, A. Cureus, 2021, 13 (7), e16247. doi:10.7759/cureus.16247. PMID:34373809.

(139) Liu, F.; Long, X.; Zhang, B.; Zhang, W.; Chen, X.; Zhang, Z. Clin. Gastroenterol. Hepatol. 2020, 18 (9), 2128. doi:10.1016/j.cgh.2020.04.040.

(140) Freire Santana, M.; Borba, M. G. S.; Baía-da-Silva, D. C.; Val, F.; Alexandre, M. A. A.; Brito-Sousa, J. D.; et al. Am. J. Trop. Med. Hyg. 2020, 103 (4), 1604. doi:10.4269/ajtmh.20-0787.

(141) Ma, L.; Xie, W.; Li, D.; Shi, L.; Mao, Y.; Xiong, Y.; Zhang, Y.; Zhang, M. medRxiv, 2020. doi:10.1101/2020.03.21.20037267.

(142) Ma, L.; Xie, W.; Li, D.; Shi, L.; Ye, G.; Mao, Y.; et al. J. Med. Virol. 2021, 93 (1), 456. doi:10.1002/jmv.26259.

(143) Eisenberg, M. L. Fertil. Steril. 2020, 113 (6), 1154. doi:10.1016/j.fertnstert. 2020.04.039.

(144) He, W.; Liu, X.; Feng, L.; Xiong, S.; Li, Y.; Chen, L.; et al. Front. Med. (Lausanne), 2020, 7, 594364. doi:10.3389/fmed.2020.594364. PMID:33330557.

(145) Pan, F.; Xiao, X.; Guo, J.; Song, Y.; Li, H.; Patel, D. P.; et al. Fertil Steril. 2020, 113 (6), 1135. doi:10.1016/j.fertnstert.2020.04.024.

(146) Valdivia, A.; Cortés, L.; Beitia, M.; Totorikaguena, L.; Agirregoitia, N.; Corcostegui, B.; et al. Reproduction, 2020, 159 (3), 241. doi:10.1530/REP19-0274.

(147) Shen, Q.; Xiao, X.; Aierken, A.; Yue, W.; Wu, X.; Liao, M.; Hua, J. J. Cell. Mol. Med. 2020, 24 (16), 9472. doi:10.1111/jcmm.15541.

(148) Mannur, S.; Jabeen, T.; Khader, M. A.; Rao, L. S. S. QJM, 2021, 114, 328. doi:10.1093/qjmed/hcab019.

(149) Holtmann, N.; Edimiris, P.; Andree, M.; Doehmen, C.; Baston-Buest, D.; Adams, O.; Kruessel, J.-S.; Bielfeld, A. P. Fertil Steril. 2020, 114 (2), 233. doi:10.1016/j.fertnstert.2020.05.028.

(150) Bendayan, M.; Boitrelle, F. EclinicalMedicine, 2020, 29, 100670. doi:10.1016/j. eclinm.2020.100670.

(151) Bulut, E. C.; Ertaş, K.; Bulut, D.; Koparal, M. Y.; Çetin, S. Andrologia, 2021, 53 (3), e13971. doi:10.1111/and.13971.

(152) Zhang, J.; Wu, Y.; Wang, R.; Lu, K.; Tu, M.; Guo, H.; et al. Preprints, 2020, 2020020307. doi:10.20944/preprints202002.0307.v1.

(153) Patell, R.; Bogue, T.; Koshy, A.; Bindal, P.; Merrill, M.; Aird, W. C.; Bauer, K. A.; Zwicker, J. I. Blood, 2020, 136 (11), 1342. doi:10.1182/ blood.2020007938.

(154) Klok, F. A.; Kruip, M. J. H. A.; van der Meer, N. J. M.; Arbous, M. S.; Gommers, D. A. M. P. J.; Kant, K. M.; et al. Thromb. Res. 2020, 191, 145. doi:10.1016/j.thromres.2020.04.013.

(155) Hu, D.; Liu, K.; Li, B.; Hu, Z. Eur. Heart J. 2020, 41 (32), 3104. doi:10.1093/ eurheartj/ehaa524.

(156) Danzi, G. B.; Loffi, M.; Galeazzi, G.; Gherbesi, E. Eur. Heart J. 2020, 41 (19), 1858. doi:10.1093/eurheartj/ehaa254.

(157) Guzik, T. J.; Mohiddin, S. A.; Dimarco, A.; Patel, V.; Savvatis, K.; Marelli-Berg, F. M.; et al. Cardiovasc. Res. 2020, 116 (10), 1666. doi:10.1093/ cvr/cvaa106.

(158) Tang, N.; Li, D.; Wang, X.; Sun, Z. J. Thromb. Haemost. 2020, 18 (4), 844. doi:10.1111/jth.14768.

(159) Driggin, E.; Madhavan, M. V.; Bikdeli, B.; Chuich, T.; Laracy, J.; Biondi-Zoccai, G.; et al. J. Am. Coll. Cardiol. 2020, 75 (18), 2352. doi:10.1016/j. jacc.2020.03.031.

(160) Varga, Z.; Flammer, A. J.; Steiger, P.; Haberecker, M.; Andermatt, R.; Zinkernagel, A. S.; et al. Lancet, 2020, 395 (10234), 1417. doi:10.1016/ S0140-6736(20)30937-5.

(161) Terpos, E.; Ntanasis-Stathopoulos, I.; Elalamy, I.; Kastritis, E.; Sergentanis, T. N.; Politou, M.; et al. Am. J. Hematol. 2020, 95 (7), 834. doi:10.1002/ajh.25829.

(162) Russell, C. D.; Fairfield, C. J.; Drake, T. M.; Turtle, L.; Seaton, R. A.; Wootton, D. G.; et al. Lancet Microbe, 2021, 2 (8), e354. doi:10.1016/ S2666-5247(21)00090-2.

(163) Sen, M.; Honavar, S. G.; Bansal, R.; Sengupta, S.; Rao, R.; Kim, U.; et al.; members of the Collaborative OPAI-IJO Study on Mucormycosis in COVID-19 (COSMIC) Study Group. Indian J. Ophthalmol. 2021, 69 (7), 1670. doi:10.4103/ijo.IJO_1565_21.

(164) Trovato, L.; Calvo, M.; Migliorisi, G.; Astuto, M.; Oliveri, F.; Oliveri, S. Respir. Med. Case Rep. 2021, 32, 101367. doi:10.1016/j.rmcr.2021.101367.

(165) Zhou, P.; Liu, Z.; Chen, Y.; Xiao, Y.; Huang, X.; Fan, X.-G. Infect. Control Hosp. Epidemiol. 2020, 41 (9), 1124. doi:10.1017/ice.2020.156.

(166) Chan, J. F.-W.; Zhang, A. J.; Yuan, S.; Poon, V. K.-M.; Chan, C. C.-S.; Lee, A. C.-Y.; et al. Clin. Infect. Dis. 2020, 71 (9), 2428. doi:10.1093/cid/ ciaa325.

(167) Nakra, N. A.; Blumberg, D. A.; Herrera-Guerra, A.; Lakshminrusimha, S. Children (Basel), 2020, 7 (7), E69. doi:10.3390/children7070069.

(168) Ludvigsson, J. F. Acta Paediatr. 2021, 110 (3), 914. doi:10.1111/apa.15673.

(169) Takia, L.; Angurana, S. K.; Nallasamy, K.; Bansal, A.; Muralidharan, J. J. Trop. Pediatr. 2021, 67, (3), fmab071. doi:10.1093/tropej/fmab071.

(170) McLendon, L. A.; Rao, C. K.; Da Hora, C. C.; Islamovic, F.; Galan, F. N. Pediatrics, 2021, 146 (6), e2020049678. doi:10.1542/peds.2020-049678.

(171) Sethuraman, U.; Kannikeswaran, N.; Ang, J.; Singer, A.; Miller, J.; Haddad, R.; Stankovic, C. Am. J. Emerg. Med. 2021, 39, 164. doi:10.1016/j. ajem.2020.10.035.

(172) Fox, S. E.; Lameira, F. S.; Rinker, E. B.; Vander Heide, R. S. Ann. Intern. Med. 2020, 173 (12), 1025. doi:10.7326/L20-0882. 
(173) Hultström, M.; von Seth, M.; Frithiof, R. J. Hypertens. 2020, 38 (8), 1613. doi:10.1097/HJH.0000000000002531.

(174) Rudnick, M. R.; Hilburg, R. Am. J. Nephrol. 2020, 51 (10), 761. doi:10.1159/ 000511161.

(175) Huang, C.; Wang, Y.; Li, X.; Ren, L.; Zhao, J.; Hu, Y.; et al. Lancet, 2020, 395 (10223), 497. doi:10.1016/S0140-6736(20)30183-5.

(176) Ding, Y.; He, L.; Zhang, Q.; Huang, Z.; Che, X.; Hou, J.; et al. J. Pathol. 2004, 203 (2), 622. doi:10.1002/path.1560.

(177) Tammaro, A.; Parisella, F. R.; Adebanjo, G. A. R. J. Cosmet. Dermatol. 2021, 20 (8), 2378. doi:10.1111/jocd.14291.

(178) McMahon, D. E.; Gallman, A. E.; Hruza, G. J.; Rosenbach, M.; Lipoff, J. B.; Desai, S. R.; et al. Lancet Infect. Dis. 2021, 21 (3), 313. doi:10.1016/S1473-3099 (20)30986-5.

(179) Guarneri, C.; Rullo, E. V.; Pavone, P.; Berretta, M.; Ceccarelli, M.; Natale, A.; Nunnari, G. Lancet Infect. Dis. 2021, 21 (1), 24. doi:10.1016/S14733099(20)30402-3.

(180) Elezkurtaj, S.; Greuel, S.; Ihlow, J.; Michaelis, E. G.; Bischoff, P.; Kunze, C. A.; et al. Sci. Rep. 2021, 11 (1), 4263. doi:10.1038/s41598-02182862-5.

(181) Clark, C. E.; McDonagh, S. T. J.; McManus, R. J.; Martin, U. J. Hum. Hypertens. 2021, 35 (4), 304 doi:101038/s41371-020-00451-X.

(182) Liu, L.; Ni, S.-Y.; Yan, W.; Lu, Q.-D.; Zhao, Y.-M.; Xu, Y.-Y.; et al. EclinicalMedicine, 2021, 40, 101111. doi:10.1016/j.eclinm.2021.101111.

(183) Ghazy, R. M.; Almaghraby, A.; Shaaban, R.; Kamal, A.; Beshir, H.; Moursi, A.; Ramadan, A.; Taha, S. H. N. Sci. Rep. 2020, 10 (1), 22139. doi:10.1038/s41598-020-77748-X.

(184) Saghir, S. A. M.; AlGabri, N. A.; Alagawany, M. M.; Attia, Y. A.; Alyileili, S. R.; Elnesr, S. S. et al. Ther. Clin. Risk Manage. 2021, 17, 371. doi:10.2147/TCRM. S301817.

(185) Nojomi, M.; Yassin, Z.; Keyvani, H.; Makiani, M. J.; Roham, M.; Laali, A.; et al. BMC Infect. Dis. 2020, 20 (1), 954. doi:10.1186/s12879-02005698-w.

(186) Lian, N.; Xie, H.; Lin, S.; Huang, J.; Zhao, J.; Lin, Q. Clin. Microbiol. Infect. 2020, 26 (7), 917. doi:10.1016/j.cmi.2020.04.026.

(187) Behera, P.; Patro, B. K.; Singh, A. K.; Chandanshive, P. D.; Pradhan, R. S. R. S. K. Pentapati, S. S. K.; et al. PLoS One, 2021, 16 (2), e0247163. doi:10.1371/journal. pone.0247163.

(188) Popp, M.; Stegemann, M.; Metzendorf, M.-I.; Gould, S.; Kranke, P. Meybohm, P.; Skoetz, N.; Weibel, S. Cochrane Database Syst. Rev. 2021, 7, CD015017. doi:10.1002/14651858.CD015017.pub2. PMID:34318930.

(189) Mendieta Zerón, H.; Meneses Calderón, J.; Paniagua Coria, L.; Meneses Figueroa, J.; Vargas Contreras, M. J.; Vives Aceves, H. L.; et al. World Acad. Sci. J. 2021, 3 (3), 23. doi:10.3892/wasj.2021.94.

(190) Kelleni, M. T. Pharmacol. Res. 2020, 157, 104874. doi:10.1016/j.phrs. 2020.104874

(191) Beigel, J. H.; Tomashek, K. M.; Dodd, L. E.; Mehta, A. K.; Zingman, B. S.; Kalil, A. C.; et al. N Engl. J. Med. 2020, 383 (19), 1813. doi:10.1056/ NEJMoa2007764.

(192) Choudhury, A.; Mukherjee, G.; Mukherjee, S. Hum Immunol. 2021, 82 (9), 649. doi:10.1016/j.humimm.2021.05.001.

(193) Agrawal, U.; Raju, R.; Udwadia, Z. F. Med. J. Armed Forces India, 2020, 76 (4), 370. doi:10.1016/j.mjafi.2020.08.004.

(194) Xu, X.; Ong, Y. K.; Wang, D. Y. Mil. Med. Res. 2020, 7 (1), 22. doi:10.1186 s40779-020-00251-X.

(195) Sanders, J. M.; Monogue, M. L.; Jodlowski, T. Z.; Cutrell, J. B. JAMA, 2020, 323 (18), 1824. doi:10.1001/jama.2020.6019. PMID:32282022.

(196) Buijsers, B.; Yanginlar, C.; Maciej-Hulme, M. L.; de Mast, Q.; van der Vlag, J. EbioMedicine, 2020, 59, 102969. doi:10.1016/j.ebiom.2020.102969.

(197) Gozzo, L.; Viale, P.; Longo, L.; Vitale, D. C.; Drago, F. Front. Pharmacol. 2020, 11, 1307. doi:10.3389/fphar.2020.01307. PMID:32973526.

(198) Hippensteel, J. A.; LaRiviere, W. B.; Colbert, J. F.; Langouët-Astrié, C. J.; Schmidt, E. P. Am. J. Physiol. Lung Cell. Mol. Physiol. 2020, 319 (2), L211. doi:10.1152/ajplung.00199.2020.

(199) Tang, X.; Feng, Y.-M.; Ni, J.-X.; Zhang, J.Y.; Liu, L.-M.; Hu, K.; et al. Respiration, 2021, 100 (2), 116. doi:10.1159/000512063.

(200) Bhattacharya, R.; Mondal, M.; Lyngdoh, L.; Chowdhury, S.; Mukherjee, R.; Naiya, S. 2020, 3, 480. doi:10.6084/m9.figshare.13172630.v1.

(201) Beck, I. M. E.; Vanden Berghe, W.; Vermeulen, L.; Yamamoto, K. R.; Haegeman, G.; De Bosscher, K. Endocr. Rev. 2009, 30 (7), 830. doi:10.1210/ er.2009-0013.

(202) Xavier, A. M.; Anunciato, A. K. O.; Rosenstock, T. R.; Glezer, I. Front Endocrinol. (Lausanne), 2016, 7, 31. doi:10.3389/fendo.2016.00031.

(203) Meijer, O. C.; Koorneef, L. L.; Kroon, J. Ann. Endocrinol. (Paris), 2018, 79 (3), 107. doi:10.1016/j.ando.2018.03.004.
(204) Adcock, I. M.; Mumby, S. Handb. Exp. Pharmacol. 2017, 237, 171. doi:10.1007| 164_2016_98. PMID:27864677.

(205) Perera, M.; El Khoury, J.; Chinni, V.; Bolton, D.; Qu, L.; Johnson, P.; et al. BMJ Open, 2020, 10 (12), e040580. doi:10.1136/bmjopen-2020-040580.

(206) Xu, X.; Ong, Y. K.; Wang, D. Y. Military Med. Res. 2020, 7 (1), 22. doi:10.1186/ s40779-020-00251-x.

(207) Trial registered on ANZCTR. The Australian New Zealand Clinical Trials Registry (ANZCTR), Camperdown NSW, Australia. 2021. Available from https://anzctr.org.au/Trial/Registration/TrialReview.aspx?id=383085\& showOriginal=true\&isReview=true (Accessed 7 December 2021).

(208) Clinical trials for eudract_number:2021-005226-26. Available from https:/| www.clinicaltrialsregister.eu/ctr-search/search?query=eudract_number\% 3A2021-005226-26 (Accessed 7 December 2021).

(209) CTRI/2021/10/037605. Clinical Trials Registry - India (CTRI). Available from http://www.ctri.nic.in/Clinicaltrials/pmaindet2.php?trialid=61940 (Accessed 7 December 2021).

(210) Hoang, K.; Abdo, T.; Reinersman, J. M.; Lu, R.; Higuita, N. I. A. Med. Mycol. Case Rep. 2020, 29, 22. doi:10.1016/j.mmcr.2020.05.008.

(211) Indari, O.; Baral, B.; Muduli, K.; Mohanty, A. P.; Swain, N.; Mohakud, N. K.; Jha, H. C. Biosaf. Health, 2021, 3 (4), 230. doi:10.1016/j. bsheal.2021.04.001.

(212) Viho, E. M. G.; Buurstede, J. C.; Mahfouz, A.; Koorneef, L. L.; van Weert, L. T. C. M.; Houtman, R.; et al. Neuroendocrinology, 2019, 109 (3), 266. doi:10.1159/000499659.

(213) Paragliola, R. M.; Papi, G.; Pontecorvi, A.; Corsello, S. M. Int. J. Mol. Sci. 2017, 18 (10), E2201. doi:10.3390/ijms18102201.

(214) Rodriguez-Morales, A. J.; Sah, R.; Millan-Oñate, J.; Gonzalez, A.; Montenegro-Idrogo, J. J.; Scherger, S.; Franco-Paredes, C.; HenaoMartínez, A. F. Ther. Adv. Infect. Dis. 2021, 8. doi:10.1177/20499361211027065.

(215) COVID-19 Treatment Guidelines Panel. Coronavirus disease 2019 (COVID-19) treatment guidelines. National Institutes of Health. 356. Available from https://www.covid19treatmentguidelines.nih.gov/.

(216) Arshad, U.; Pertinez, H.; Box, H.; Tatham, L.; Rajoli, R. K. R.; Curley, P.; et al. Clin. Pharmacol. Ther. 2020, 108 (4), 775. doi:10.1002/cpt.1909.

(217) Anand, U.; Jakhmola, S.; Indari, O.; Jha, H. C.; Chen, Z.-S.; Tripathi, V.; Pérez de la Lastra, J. M. Front. Immunol. 2021, 12, 658519. doi:10.3389/ fimmu.2021.658519. PMID:34276652.

(218) Stebbing, J.; Phelan, A.; Griffin, I.; Tucker, C.; Oechsle, O.; Smith, D.; Richardson, P. Lancet Infect. Dis. 2020, 20 (4), 400. doi:10.1016/S1473-3099 (20)30132-8.

(219) Deng, F.; Gao, D.; Ma, X.; Guo, Y.; Wang, R.; Jiang, W.; Gong, S. Ir. J. Med. Sci. 2021, 190 (1), 29. doi:10.1007/s11845-020-02287-3.

(220) Alnomasy, S. F.; Alotaibi, B. S.; Aldosari, Z. M.; Mujamammi, A. H.; Anand, P.; Akhter, Y. A.; Hasan, M. R. 2021, 1. doi:10.21203/rs.3.rs-191980/v1.

(221) Sangtani, R.; Ghosh, A.; Jha, H. C.; Parmar, H. S.; Bala, K. Phytother. Res. 2021, 35 (5), 2296. doi:10.1002/ptr.6948.

(222) Kashyap, D.; Jakhmola, S.; Tiwari, D.; Kumar, R.; Moorthy, N. S. H. N.; Elangovan, M.; Brás, N. F.; Jha, H. C. J. Biomol. Struct. Dyn. 2021, 1. doi:10. 1080/07391102.2021.1947384

(223) Feld, J. J.; Kandel, C.; Biondi, M. J.; Kozak, R. A.; Zahoor, M. A.; Lemieux, C.; et al. Lancet Respir. Med. 2021, 9 (5), 498. doi:10.1016/S22132600(20)30566-X.

(224) Cathcart, A. L.; Havenar-Daughton, C.; Lempp, F. A.; Ma, D.; Schmid, M.; Agostini, M. L.; et al. bioRxiv, 2021. doi:10.1101/2021.03.09.434607.

(225) O'Brien, M. P.; Forleo-Neto, E.; Musser, B. J.; Isa, F.; Chan, K.-C.; Sarkar, N.; et al. N. Engl. J. Med. 2021, 385, 1184. doi:10.1056/NEJMoa2109682.

(226) Strope, J. D.; Chau, C. H.; Figg, W. D. Seminars Oncol. 2020, 47 (5), 335. doi:10.1053/j.seminoncol.2020.06.002.

(227) Zafari Zangeneh, F.; Sarmast Shoushtari, M. J. Family Reprod. Health, 2021, 15 (3), 150. doi:10.18502/jfrh.v15i3.7132. PMID:34721606.

(228) Al-Lami, R. A.; Urban, R. J.; Volpi, E.; Algburi, A. M. A.; Baillargeon, J. Mayo Clinic Proc. 2020, 95 (8), 1710. doi:10.1016/j.mayocp.2020.05.013.

(229) Li, K.; Chen, G.; Hou, H.; Liao, Q.; Chen, J.; Bai, H.; et al. Reprod. BioMed. Online, 2021, 42 (1), 260. doi:10.1016/j.rbmo.2020.09.020.

(230) Pozzilli, P.; Lenzi, A. Metabolism, 2020, 108, 154252. doi:10.1016/j.metabol. 2020.154252.

(231) Shah, S. B. Endocr. Metab. Sci. 2021, 5, 100109. doi:10.1016/j.endmts.2021. 100109.

(232) Fragkou, P. C.; Dimopoulou, D. Metabolism Open, 2021, 12, 100145. doi:10. 1016/j.metop.2021.100145.

(233) Jęśkowiak, I.; Wiatrak, B.; Grosman-Dziewiszek, P.; Szeląg, A. Vaccines, 2021, 9 (5), 502. doi:10.3390/vaccines9050502. 